\title{
Algunas cuestiones en torno a la elite de Carteia
}

\author{
Aurelio Padilla Monge \\ Universidad de Sevilla \\ apadilla@us.es
}

\section{RESUMEN}

El análisis antroponímico de los miembros de la oligarquía de Carteia indica la existencia de una mayoría de individuos descendientes de la base demográfica hispano-romana a la que se refiere Livio (43.3.2) o de inmigrantes llegados desde Italia con posterioridad, pero también indica la presencia de algunos personajes descendientes de los habitantes de la Carteia púnica que eligieron integrarse en la nueva colonia latina (Livio, 43.3.4).

Palabras clave: Antroponimia antigua, Bética romana, emigración itálica.

\section{Some questions about the elite of Carteia}

\begin{abstract}
The anthroponomastic analysis of the members of the oligarchy of Carteia proves the existence of most descendants from the Hispano-Roman people to whom Livy (43.3.2) refers, or from incomers who arrived later from Italy. Nevertheless, this analysis also shows the presence of some descendants from the inhabitants of Punic Carteia who chose to live in the new Latin colony (Livy, 43.3.4).
\end{abstract}

Key words: Ancient anthroponymy, Roman Baetica, Italian emigration.

Carteia, cuyas ruinas se sitúan en el entorno del Cortijo el Rocadillo (San Roque, Cádiz), fue fundada por los cartagineses en el primer cuarto del siglo IV a.C., en la margen izquierda y a tres kilómetros de la actual desembocadura del río Guadarranque y al Suroeste de la colonia fenicia documentada en el Cerro del Prado (San Roque), fundada en el siglo VII a.C. Como indica Mela, Carteia se pobló con fenicios traídos desde África (transvecti ex Africa phoenices) ${ }^{1}$. Timóstenes de Rodas, almirante de Ptolomeo II Filadelfo, la incluyó en su obra Sobre los puertos, en la que habla de su

${ }^{1}$ Mela 2.96. 
gran muralla y sus dársenas ${ }^{2}$. Fue utilizada como base naval por los romanos en la Segunda Guerra Púnica ${ }^{3}$.

En 171 a.C., Roma estableció en esta población a más de 4000 hombres, hijos de soldados romanos y mujeres hispanas ${ }^{4}$. La nueva comunidad quedó constituida como colonia latina Libertinorum ${ }^{5}$. En ella quedaron integrados los habitantes de la Carteia púnica que quisieron quedarse en la colonia latina ${ }^{6}$.

La inscripción $A E$ 1981, 5177, parece reflejar el estatuto de municipium que Carteia probablemente disfrutaba cuando Augusto estaba en el poder. La fórmula IIIIvir iterum $^{8}$ confirma epigráficamente el estatuto municipal de Carteia, obviamente de derecho romano, visto el status previo de colonia latina que disfrutaba esta comunidad, en la que se documentan la tribu Sergia y la Galeria ${ }^{10}$.

Así pues, es esperable encontrar entre los miembros de la elite carteyense, por un lado, descendientes de los hijos de los soldados romanos y las mujeres hispanas, por otro, descendientes de algunos de los fenicios norteafricanos asentados en su momento por Cartago y, por último, individuos inmigrantes o descendientes de inmigrantes. Por el contrario, a priori, parece poco probable que documentemos dentro de la elite de Carteia a individuos de la vieja base demográfica indígena ${ }^{11}$, pues, que se sepa, no quedaron integrados como colectivo en la colonia latina Libertinorum ${ }^{12}$, a no ser que se trate de hispanos llegados desde otras poblaciones y asentados en Carteia.

2 Strab. 3.1.7.

${ }^{3}$ Liv. 28.30.6.

${ }^{4}$ Liv. 43.3.2: ex militibus Romanis et ex Hispanis mulieribus, cum quibus connubium non esset, natos.

${ }^{5}$ Liv. 43.3.4.

${ }^{6}$ Liv. 43.3.4: qui Carteiensium domi manere vellent, potestatem fieri, uti numero colonorum essent.

7 [- - ] aliqui [- - - / - - ] in munic[ipio - - - ].

8 J. GonZÁlez, Inscripciones romanas de la provincia de Cádiz, Cádiz, 1982 (=IRPCádiz), 92.

9 IRPCádiz 92.

${ }^{10} A E$ 1981, 518 y CIL II, 1929.

${ }^{11}$ La identificación de los individuos originarios de la península Ibérica (hispani) es fácil cuando las fuentes transmiten una antroponimia indígena. Pero la situación se complica cuando se trata de individuos con onomástica personal latina. Durante la etapa pre-imperial, muchos indígenas se atribuyeron nomina romanos sin cumplir el requisito previo de la obtención del derecho de ciudadanía, apropiación onomástica consecuencia del establecimiento de relaciones de clientelismo entre nativos hispanos y personajes de la nobilitas romana, especialmente aquellos que gobernaron las provincias hispanas y, a veces, como destaca R. C. KNAPP, "The Origins of Provincial Prosopography in the West", AncSoc 9, 1978, 192-196, miembros de sus Consilia. Este fenómeno, como adelanta C. GonzÁLeZ Román, "La onomástica del «Corpus» cesariano y la sociedad de la Hispania meridional", Studia Hist. Hist. Antig. 4-5, 1986-1987, 74, debió de ser habitual durante el siglo II a.C. Pero está no fue la única vía de difusión de la onomástica latina, pues, como defiende Ju. B. Tsirkin, "Romanization of Spain: Sociopolitical Aspects (II). Romanization in the Period of the Republic", Gerión 11, 1993, 310-311, también se produjo la probable adopción por parte de los indígenas, por variadas razones, de los nombres de los italianos con los que convivían.

12 A no ser que admitamos la traducción hace años propuesta por M. J. PenA, "Nota sobre Livio, XLIII, 3: la fundación de la colonia de Carteia", Espacio, Tiempo y Forma. Historia Antigua 1, 1988, 276, del fragmento de Livio que trata de estos temas carteyenses en concreto, especialmente en la parte que dice «el Senado decretó que inscribieran ante L. Canuleio sus nombres y los de aquellos a quienes él hubiese manumitido», pues de ella se deriva la posibilidad de que se integraran en Carteia 


\section{Los miembros documentados de la elite carteyense ${ }^{13}$ son los siguientes ${ }^{14}$ :}

\section{Agri(us), censor $^{15}$ de 95 a.C. ${ }^{16}$ - Los pocos Agrii de la Bética ${ }^{17}$ carecen de antece- dente nominal entre los magistrados pre-imperiales con mando en Hispania Ulterior}

indígenas hispanos, previamente esclavizados (no necesariamente por los romanos), manumitidos por L. Canuleyo.

${ }^{13}$ Consideramos núcleo fundamental de las elites municipales a aquellos individuos que ocuparon los cargos superiores (magistraturas, sacerdocios y decurionato) en el gobierno de sus respectivas comunidades y a sus familias. Pero también debemos considerar en este estudio a aquellas personas cuya pertenencia a dicho rango es al menos presumible a partir de sus relaciones con miembros de las oligarquías o con la institución corporativa de estas y a aquellos personajes no ajenos a las comunidades que realizaron actos de munificencia de singular importancia, siempre que no haya indicios del carácter libertino de los individuos en cuestión, en cuyo caso quedarían excluidos.

${ }^{14}$ Como se verá a continuación, una buena cantidad de los nomina que van a ser analizados dentro de la antroponimia carteyense son de origen osco. Como destaca M. J. PenA, "Algunos rasgos dialectales del latín de Hispania", Faventia 12-13, 1-2, 1990-1991, 390-393, el origen osco de la más temprana colonización de la península Ibérica se documenta en rasgos dialectales oscos que aparecen en el latín de las áreas en las que la presencia romana fue más antigua (valle del Guadalquivir, valle del Ebro, costa mediterránea e isla de Mallorca), rasgos entre los cuales destaca el nominativo singular en - $i$, fenómeno ciertamente común a varias lenguas itálicas, pero que en el osco se presenta con mayor claridad. Asimismo, según M. J. Pena, son relativamente abundantes en la península Ibérica los nombres propios (entre los que sobresalen los de magistrados monetales de Valentia, Carthago Nova, Calagurris, Saguntum y Carteia) que presentan esta estructura, aunque, con frecuencia, defiende la autora, no son reconocidos como tales, sino como nominativos en -ius abreviados. M. J. Pena cataloga dentro de esta categoría a los magistrados carteyenses que aparecen en las leyendas monetales como Agri, Ami, Atini, Curvi, Iuli, Marci, Mini, Rai y Vibi. No estoy en condiciones de discutir las opiniones científicas de M. J. Pena, porque no soy lingüista; pero sí puedo plantear algunas objeciones. No todos los nomina que presumiblemente tienen un nominativo en - $i$ (o sea, que se supone que no están abreviados en la leyenda monetal) son origen osco, pues algunos presentan mayores probabilidades de ser latinos. Tal es el caso de Curvi(us), Iuli(us) y Marci(us). Por el contrario, sí parecen cumplir las dos condiciones de origen osco y (aparente) nominativo en -i Atini, Mini, Nini, Rai y Vibi. En una situación intermedia se sitúan Agri y Ami, pues ambos nomina parecen ser de origen latino, pero se atestiguan más abundantemente en Campania y otros territorios no latinos, de manera que no puede desestimarse rotundamente un remoto origen osco. Sin embargo, poseemos el ejemplo de Maius, un nomen de origen osco que no se presenta abreviado y que excluye la forma de nominativo en $-i$, aunque se trata de un ejemplo bastante más tardío que los demás. Asimismo, Num, en cualquiera de sus tres posibles desarrollos, esto es, Num(isius), Num(erius) y Num(mius), corresponde a un nomen de origen osco cuya forma en la leyenda monetal es una evidente abreviatura que no puede confundirse con un nominativo en - $i$. Por el contrario, se documenta un Pedecai de, al parecer, inequívoco origen latino que es abreviatura de Pedecaius y que no parece que deba ser interpretado como un nominativo en -i. Por último, otros nomina, como Arg(ius), Cur(manus) y Sep(timius), se presentan evidentemente abreviados y demuestran que los nomina en las leyendas monetales carteyenses pueden aparecer abreviados. Por estas razones, vamos a considerar que los nomina aparentemente abreviados están efectivamente abreviados y todos serán desarrollados con terminaciones latinas en -us.

${ }^{15}$ A. Vives, La moneda hispánica, Madrid, 1926-1928 (desde ahora, A. Vives, MH), CXXVII, y O. GiL, La moneda hispánica en la edad Antigua, Madrid, 1966 (desde ahora, O. Gil, MHEA), n 1240. L. Agri(us) aparece en la emisión como censor en compañía de L. Rai(us).

${ }_{16}$ F. Chaves, Las monedas hispano-romanas de Carteia, Barcelona, 1979, 129. Posterior a 45 a.C., según O. GiL, MHEA, nº 347, y F. BeLtrán Lloris, "Los magistrados monetales en Hispania", Numisma 150-155, 1978, 193.

${ }^{17}$ Se reducen a cuatro testimonios epigráficos; véase J. M. ABASCAL, Los nombres personales en las inscripciones latinas de Hispania, Murcia, 1994 (desde ahora, Abascal), 73. Sin embargo, dentro del

2011, vol. 29, núm. 1, 239-263 
(desde ahora, HU). Además, no se atestigua ningún Agrius entre los magistrados del Estado romano de los siglos II-I a.C.

L. Agr(ius) probablemente era descendiente de uno de los hijos de soldados romanos y nativas asentados en la colonia ${ }^{18} \mathrm{o}$ bien era inmigrante italiano o descendiente de inmigrante italiano ${ }^{19}$. En este sentido, debe destacarse que el nomen Agrius se atestigua en el Lacio y Campania y, en menor grado, entre samnitas y volscos ${ }^{20}$, de forma que no puede desestimarse un remoto origen osco, aunque se le considera latino ${ }^{21}$.

Cn. $\underline{\text { Am }}$ (m)i(us), aed(ilis ${ }^{22}$ de 90 a.C. ${ }^{23}$ - Los pocos Ammii documentados epigráficamente en la Bética ${ }^{24}$ no cuentan con antecedente nominal entre los magistrados preimperiales con mando en esta provincia. Además, no se atestigua ningún Ammius entre los magistrados del Estado romano de los siglos II-I a.C. A pesar del bajo número de Ammii documentados no sólo en la Bética sino en toda Hispania, los atestiguados en la península Ibérica alcanzan un elevado número, dentro de la zona latina de la Europa romana ${ }^{25}$. En buena medida, esto se debe a la existencia de una forma autóctona cuyos testimonios al parecer son difíciles de distinguir de los de la forma latina ${ }^{26}$.

territorio latino de la Europa romana, en donde Dalmacia ocupa el primer lugar, con casi el $60 \%$ de los testimonios epigráficos documentados, Hispania ocupa el segundo lugar, con el $22 \%$, por delante de Galia Cisalpina, con solo el 7,4 \%; véase B. LöRINCZ \& F. REDÖ, Onomasticon provinciarum Europae latinarum. Vol. I: Aba-Bysanus, Budapest, 1994 (desde ahora, Lörincz \& Redö, OPEL I), 59.

18 J. S. Hernández, "Tito Livio XLIII, 3 y los nomina de los magistrados monetales de Carteia", Faventia 16, 2, 1994, 88-89. En Mirobriga-Santiago do Cacém (Setúbal, Portugal), se documenta un tal C. Agrius Rufus, adlectus italicensis (AE 1964, 276). Como indica U. Espinosa, "Riqueza mobiliaria y promoción política; los Mamili de Tritium Magallum", Gerión 6, 1988, 264, cuando se refiere a T. Mamilius Silonis fil. Quir. Praesens, que recibió la adlectio Italica, la expresión no indica que fuera elevado al orden decurional de la ciudad de Italica, en el sentido de adlectus inter decuriones Italicae, como considera L. A. Curchin, The Local Magistrates of Roman Spain, Toronto, 1990, 152, a C. Agrius Rufus, sino que se trataría, como defiende A. Montenegro, "Problemas y nuevas perspectivas en el estudio de la Hispania de Vespasiano", HA 5, 1975, 28-29, de un caso más de homologación de un hispano al ius Italicum a efectos militares, pues los hispanos, al integrarse genéricamente, desde Vespasiano, en el ius Latium fueron considerados itálicos; véase también J. GAGÉ, "Italica adlectio", REA 71, 1969, 65-84.

19 Para evitar repeticiones molestas e innecesarias, a partir de ahora, si no se indica lo contrario, se dará por sabido que el origen del emigrante es Italia.

${ }^{20}$ Véase R. S. Conway, The Italic Dialects, Darmstadt, 1967r $, 155,343,188$ y 257.

21 H. Solin y O. Salomies, Repertorium nominum gentilium et cognominum latinorum, Hildesheim, $1988,10$.

22 A. Vives, $M H$, CXXVII, 5-6, y O. GiL, MHEA, $\mathrm{n}^{\text {os }} 1238-1239$. Su colega en la emisión es $L$. $\operatorname{Arg}(---)$.

23 F. Chaves, Las monedas hispano-romanas..., 129-130; "Carteia (Cortijo de Rocadillo. San Roque. Cádiz)", en P. P. Ripollès \& J. M. Abascal, Catálogo del Gabinete de Antigüedades. II. Monedas y medallas. II. 1. Monedas españolas. II.1.1. Monedas hispánicas, Madrid, 2000 (desde ahora Monedas hispánicas), 282-283. De 45 a.C., según O. GIL, MHEA, nº 347.

${ }^{24}$ Véase ABASCAL, 76.

${ }^{25}$ Hispania alcanza el 64,7 \% del total; véase LörincZ y REDö, OPEL I, 99.

26 Abascal, 75. Véase también J. M. Vallejo, Antroponimia indígena de la Lusitania romana (Anejos de Veleia, Series Minor 23), Vitoria, 2005, 130-131. 
A pesar de esta dificultad, $\mathrm{Cn}$. Am(m)i(us) probablemente era descendiente de uno de los hijos de soldados romanos e hispanas asentados en la colonia ${ }^{27}$, si no era inmigrante o descendiente de inmigrante. El nomen Ammius se documenta en una amplia zona de Italia (territorio de volscos, faliscos y daunios y Campania y Calabria) ${ }^{28}$, por lo que, aunque se le considera latino ${ }^{29}$, podría tener un remoto origen osco.

C. Annius $\boldsymbol{C}$. $\boldsymbol{f}$. Gal. Senecio ${ }^{30}$, probablemente comerciante en salazones y salsas saladas de pescado, de la primera mitad del siglo I.- Los Annii de la Bética quizá solo posean el antecedente de C. Annius T. f. T. $n$. (Luscus), que pudo ser procónsul bien en $\mathrm{HC}$, bien en HU, bien en ambas provincias a la vez, en 81 a.C. ${ }^{31}$, una actuación tan tardía que no explica satisfactoriamente la gran difusión del nomen Annius entre los indígenas meridionales. Sin embargo, Hispania, en donde este nomen ocupa el puesto decimoséptimo ${ }^{32}$, se sitúa en el primer lugar por el número de testimonios epigráficos documentados en las regiones latinas de la Europa romana ${ }^{33}$. Cabe, pues, la posibilidad de que no sólo C. Annius (Luscus) hubiera actuado en HU, sino que otros Annii hicieran lo mismo en 170, 156, 135, 131, 129, 128, 119 ó 105, años de los que ignoramos qué gobernadores actuaron en $\mathrm{HU}$ y durante los cuales los Annii mantuvieron importancia dentro de la oligarquía romana.

Por otra parte. Senecio ${ }^{34}$ es un cognomen formado a partir del radical $\sqrt{ } * \operatorname{sen}(o)$-, 'viejo', presente tanto en latín como en celta, cuyas realizaciones latinas tienden a vocalismo en -i- (Senica, Senicius, Senicianus), mientras las indígenas (celtas) presentan un vocalismo en -e-, no alterado por metafonía (Senecio, Seneca) ${ }^{35}$, e incluso en -a- (Senaca, Senacianus, Senario), que hace probable la ascendencia hispana ${ }^{36}$, incluida la meridional, de C. Annius Senecio ${ }^{37}$. Así pues, este Annius quizá fuera hispano.

Por otra parte, en el pecio de Cala Rossano, en las costas del Lacio, se ha encontrado el nombre del comerciante C. Annius Senecio, muy probablemente nuestro Annius carteyense, sobre ánforas Dressel 8, algunas de las cuales contenían g(ari) sc(ombri)

27 J. S. Hernández, "Tito Livio XLIII, 3 y los nomina de los magistrados monetales de Carteia"..., 89-90.

${ }^{28}$ Véase R. S. Conway, The Italic Dialects..., 32, 36, 151, 257 y 350.

${ }^{29}$ H. Solin y O. Salomies, Repertorium nominum..., 14.

${ }^{30} A E$ 1981, 518.

31 T. R. S. Broughton, The Magistrates of the Roman Republic, II, Cleveland-Ohio, 1968, 77.

${ }^{32}$ Con 137 testimonios; véase ABASCAL, 76-78.

33 LÖRINCZ y REDÖ, OPEL I, 119-121, recogen 309 testimonios de los cuales 97 corresponden a Hispania, 74 a Galia Cisalpina y 47 a la Narbonense.

${ }^{34}$ H. Solin y O. Salomies, Repertorium nominum..., 400.

${ }^{35}$ A. Tovar, Estudios sobre las primitivas lenguas hispánicas, Buenos Aires, 1949, 149; J. M. VAlLeJo, Antroponimia indígena..., 399.

${ }^{36}$ E. W. Haley, Baetica felix: People and prosperity in Southern Spain from Caesar to Septimius Severus, University of Texas, 2003, 63.

37 Dentro de las regiones latinas de la Europa romana, Galia Cisalpina ocupa el primer lugar, con casi el $28 \%$ del total de testimonios epigráficos, e Hispania el segundo, con el 17,6 \%; véase B. Lörincz, Onomasticon provinciarum Europae latinarum. Vol. IV: Quadratia-Zures (Wien 2002) (desde ahora, Lörincz, OPEL IV), 65. 
$f(l o s)^{38}$, dato que vincula directamente a $C$. Annius Senecio con los intereses salserosalazoneros y que justifica plenamente su presencia en la misma Carteia, en el caso de que no fuera oriundo de esta población.

En efecto, Carteia era un centro de importancia en el ámbito de la producción de salazones y salsas saladas de pescado. Plinio el Viejo, al hablar de las observaciones hechas acerca de los pulpos por M. Lúculo, procónsul en la Bética, consideraciones publicadas por Trebio Níger, que era de su séquito, nos hace saber que Carteia, independientemente de que las hubiera tenido ya con antelación, poseía fábricas de salazones en época romana ${ }^{39}$, concretamente a mediados del siglo II a.C. Es además bastante probable que el inicio de las actividades pesquero-conserveras centradas en la vecina Baelo se debiera también a la iniciativa de los habitantes de Carteia, a cuyo círculo económico se vinculó la población belonense ${ }^{40}$. En este sentido, se ha puesto de relieve que el inicio de las actividades pesquero-conserveras en Baelo se produjo también a mediados del siglo II a.C., una generación después de la fundación de la colonia latina de Carteia $^{41}$, unas actividades pesquero-conserveras cuyas necesidades de numerario quedaron cubiertas durante algún tiempo por las monedas de Carteia $^{42}$. Esta dependencia de Carteia se ve reforzada por el hecho de que la figlina de El Rinconcillo, ubicada en la bahía de Algeciras y gestionada desde Carteia ${ }^{43}$, suministraba las ánforas a Baelo, para servir de contenedores de las salazones y salsas saladas de pescado producidas en la ensenada de Bolonia ${ }^{44}$, lugar hasta donde quizá algunas pudieron llegar conteniendo sal, solución que permitía lastrar adecuadamente los navíos y rentabilizar los viajes. Esta amplia dedicación a las actividades pesquero-conserveras explica, como destaca M. P. García-Bellido ${ }^{45}$, que Carteia no emitiera ases, sino semises y cuadrantes, pues el numerario de Carteia no se acunó para facilitar el cambio del denario, sino que tenía como objetivo cubrir los salarios del personal dedicado a la industria pesquera y al tráfico portuario ${ }^{46}$.

38 F. P. Arata, "Un relitto da Cala Rossano (Ventotene). Tituli picti su anfore e bollo su lingotti di stagno", en Epigrafia della produzione e della distribuzione, Roma, 1994, 480 y 484.

39 Plin., NH. 9, 89-92.

40 D. Bernal, A. Arévalo \& A. M. SÁez, "Nuevas evidencias de la ocupación en época republicana (ss. II-I a.C.)", en A. Arévalo \& D. Bernal (eds.), Las cetariae de Baelo Claudia. Avance de las investigaciones arqueológicas en el barrio meridional (2000-2004), Cádiz, 2007, 352.

41 Idem 347.

42 E. Gozalbes, "Economía de Tarifa en la Antigüedad", Aljaranda 24, 1997, 11.

43 D. Bernal \& R. JimÉnez-CAmino, "El taller de El Rinconcillo en la Bahía de Algeciras. El factor itálico y la economía de exportación (ss. I a.C.-I d.C.)”, en L. Lagóstena \& D. Bernal (eds. lits.), Figlinae Baeticae: talleres alfareros y producciones cerámicas en la Bética romana (ss. II a.C.-VII d.C.), II, Cádiz, 2004, 602.

44 Ibidem.

45 "Los ámbitos de uso y función de la moneda en la Hispania republicana", en Italia e Hispania en la crisis de la República romana. Actas del III Congreso Hispano-Italiano, Madrid, 1998, $195-196$.

46 La distribución interna de los productos salsero-salazoneros carteyenses puede seguirse en parte por los ladrillos y las tejas con la marca M. Petrucidius M.f. leg. pro pr., situables en tiempos de Augusto (de poco antes de 27 a.C., según M. Ferreiro, "Inscripciones relativas a Asta Regia", Gades, 11, 1983, 95, y de 15 / 14 a.C., en opinión de J. González, "M. Petrucidius M. f. legatus pro pr.”, Athenaeum 67, 1989, 522-523), hallados en Asta Regia (CIL I², 2298a; CIL II, 4967, 1a; IRPCádiz 33), Siarum (AE 1990, 531; HEp 3, 1993, 357; CILA II, 955), Ilipa (CIL I², 2298a; CIL II, 4967, la; CILA II, 332) e Italica 
Es probable que C. Annius Senecio fuera oriundo de Acci-Guadix (Granada) o descendiente de algún Annius de esa familia accitana llegado desde dicha población. En efecto, hay una inscripción hallada en Graena (Granada) ${ }^{47}$, pero atribuible a la colonia Iulia Gemella Acci, por la que sabemos de la existencia de C. Annius M. f. Gal(eria), [sacerdos] Innonis, de su esposa Iuflia] y de sus hijos C. Annius $C$. f. Ga[l(eria) Senecio?], M. Annius C.f. Gal(eria) Ruf[us], [sacerdos] Herculis, L. An[nius C.f. Gal(eria)] Senecio y S. Annius [C. f. Gal(eria) ---].

J. A. Delgado ${ }^{48}$ identifica a C. Annius C. $f$. Ga[l. Senecio?] con el personaje que aparece en la inscripción de Carteia, en donde existe otro sacerdos Herculis, Q. Cornelius Senecio Annianus ${ }^{49}$, al que, por su onomástica, su probable origen carteyense, su adscripción a la tribu Galeria e incluso la coincidencia del cargo sacerdotal, considera como posible pariente de los Anni documentados en Graena, a través de una probable línea parental colateral. C. Castillo ${ }^{50}$ conjetura un enlace entre las familias gaditanas de los Annii y los Cornelii, recordándonos que el rico caballero Cornelius Senecio ${ }^{51}$, de origen bético según A. Caballos ${ }^{52}$, era amigo del cordobés Séneca. Sin embargo, como hemos visto, es posible e incluso probable la relación directa de los QQ. Cornelii de Carteia con los Anni de Acci.

En efecto, Fr. Des Boscs ${ }^{53}$ defiende que las correspondencias entre C. Annius Senecio, comerciante de salazones y salsas saladas de pescado durante la primera mitad del siglo I actuando en Carteia, y el senador Q. Cornelius Senecio Annianus, que inició su carrera bajo Hadriano y que era originario de Carteia, ciudad reputada por su producción salsero-salazonera, así como la proximidad de la onomástica de ambos

(CIL I² 2298b; AE 1908, 7; CILA II, 581), procedentes de talleres costeros ubicados seguramente en la propia Carteia (AE 1952, 111, IRPCádiz 96c, CIL I², 2298a; CIL II, 4967, la; HEp 2, 266; IRPCádiz 89; $A E$ 1982, 546; AE 1990, 531a; HEp 2, 1990, 266; IRPCádiz 89, CIL II 4967,01b y CIL II 4967,01c), pues, en opinión de G. CHIC y E. GARCía, "Alfares y producciones cerámicas en la provincia de Sevilla. Balance y perspectivas”, en L. Lagóstena y D. Bernal (eds.), Figlinae Baeticae: Talleres alfareros y producciones cerámicas en la Bética romana (ss. II a.C.-VII d.C.). Actas del Congreso Internacional, I, Oxford, 2004, 311, es posible que llegaran como lastre de los barcos de transporte que subían por el Guadalquivir trayendo salazones o salsas saladas de pescado envasadas en ánforas.

47 HEp 2, 1990, 403= HEp 5, 1995, 347: Dis Manib[us Sacrum] / C(aio) Ann/io M(arci) f(ilio) Gal(eria) [sacerdoti] / Iunonis an(norum) LX Iu[lia --- sac(erdos)] / an(norum) L C(aio) Ann/io C(aii) f(ilio) Ga[l(eria) Senecioni an(norum ---] / M(arco) Ann/io C(aii) f(ilio) Gal(eria) Ruf[o sacerdoti] / Herculis an(norum) XXIII L(ucio) An[nio C(aii) f(ilio) Gal(eria)] / Senecioni an(norum)[---] S(exto) Ann/io [C(aii) f(ilio) Gal(eria) an(norum) ---] / h(ic) s(iti) s(unt) s(it) te(rra) [l(evis)], según el desarrollo propuesto por J. A. Delgado, "El culto a Júpiter, Juno y Minerva entre las élites béticas durante el Alto Imperio Romano", Gerión 11, 1993, 361.

48 Idem, 360.

${ }^{49}$ CIL II, 1929.

50 "Los senadores béticos. Relaciones familiares y sociales", en Atti del Colloquio Internazionale AIEGL su Epigrafia e Ordine Senatorio. Roma, 14-20 maggio 1981. Tituli 5, 1982, 470-471.

${ }^{51}$ Véase S. Demougrn, Prosopographie des chevaliers romains Julio-Claudiens, Roma, 1992, 466467, y Fr. Des Boscs-Plateaux, Un partie hispanique à Rome? Ascension des élites hispaniques et pouvoir politique d'Auguste à Hadrien (27 av. J.-C. - 138 ap. J.-C.), Madrid, 2005, 636-637.

52 "Los caballeros romanos originarios de las provincias de Hispania. Un avance", en L'ordre équestre. Histoire d'une aristocratie (II' siécle av. J.-C. - III siécle ap. J.-C.), Roma, 1999, 493.

53 "La richesse des aristocraties de Bétique et de Tarraconaise (50 av. J.-C.- fin du IIème siècle ap. J.-C.): essai de synthèse", Gerión 22, 1, 2004, 337. 
personajes invitan a creer que el primero era un ancestro del segundo. Así, para Fr. Des Boscs, la presencia del nomen y cognomen del mercator en la nomenclatura del senador, ambos como cognomina, induce a pensar en una alianza matrimonial entre los QQ. Cornelii y los Annii. Esta es una posibilidad. Otra es que el senador Q. Cornelius Senecio Annianus fuera descendiente de un Annius Senecio accitano afincado en Carteia, por ejemplo, un hijo del negotians salsarius o salsamentarius C. Annius Senecio, adoptado por un Q. Cornelius asentado en Carteia. En el caso de que así hubiera sucedido, las herencias unidas del padre biológico y del adoptivo habrían cimentado el encumbramiento social del adoptado (desde la adopción, ${ }^{*} Q$. Cornelius Annianus), que culminaría en la carrera de su hijo Q. Cornelius Senecio Annianus.

L. $\boldsymbol{A r g}(---)$, aed (ilis) $)^{54}$ de 90 a.C. ${ }^{55} ; \boldsymbol{L} . \boldsymbol{A r}(---)$, magistrado $^{56}$ de 80 a.C. ${ }^{57}$, y $\boldsymbol{M} . \boldsymbol{A r g a}(-$ --), magistrado ${ }^{58}$ de 70 a.C. ${ }^{59}$ - El primer problema que surge cuando se analizan estos tres casos es saber si se trata de tres miembros de la misma familia, portadores del mismo nomen, aunque abreviado de tres formas distintas, o no. Caben, pues, varias posibilidades: a) que se trate de tres individuos no emparentados; b) que $L$. $\operatorname{Arg}(---)$ y $L$. $\operatorname{Ar}(---)$ sean parientes, incluso la misma persona, y $M$. Arga(---) un tercer individuo no relacionado familiarmente con los dos anteriores, y c) que los tres individuos estén emparentados, incluyendo la posibilidad de que $L$. $\operatorname{Arg}(---)$ y $L$. $\operatorname{Ar}(---)$ sean la misma persona.

La vinculación familiar entre $L . \operatorname{Arg}(---)$ y $L$. $\operatorname{Ar}(---)$, incluso que se trate de la misma persona, no parece una posibilidad descabellada sino la más probable, pues ambos presentan idéntico praenomen, Lucius.

Si se admite que el nomen de Lucius es $\operatorname{Arg}(---)=\operatorname{Ar}\left(g_{---}\right)$, y no $\operatorname{Arg}(a---)$, y estuviésemos ante un nomen latino, esta forma, como indica J. S. Hernández ${ }^{60}$, podría ser la abreviatura de Argius, Arginnus, Argenaeus, Argentarius, Argentilius, Argentonius o Arguetius. Si se admite esta opción, aunque sólo se documenten en Hispania Argentarius y Argentilius $^{61}$, estos $\operatorname{Arg}(---)$, sea cual sea el desarrollo que elijamos para el nomen, pueden ser considerados preferentemente descendientes de uno de los medio romanos asentados en la colonia o, como la otra opción, inmigrantes o descendientes de inmigrante.

La lectura $\operatorname{Arg}(---)$ también podría relacionarse con cognomina que desarrollan la raíz indoeuropea $\sqrt{*} \operatorname{ar}(e) \hat{g}_{-}:$* $r \hat{g} i-$, 'brillante, blanquecino', corriente en toda Hispania, no sólo en la Citerior (desde ahora, HC), y con realizaciones como Arga, Argae-

54 A. Vives, $M H$, CXXVII, 5-6, y O. GiL, MHEA, $\mathrm{n}^{\text {os }}$ 1238-1239. Su colega en la emisión es $C n$. $\operatorname{Am}(m) i(u s)$.

${ }_{55}$ F. Chaves, Las monedas hispano-romanas..., 129-130; Monedas Hispánicas, 282-283.

56 A. Vives, $M H$, CXXIX, 9-10, y O. GIL, MHEA, $\mathrm{n}^{\text {os }}$ 1225-1226. Aparece junto a su colega $M$. Cur(manus).

57 F. Chaves, Las monedas hispano-romanas..., 133-134; Monedas Hispánicas, 283.

58 A. Vives, MH, CXXVII, 10, y O. GiL, MHEA, no 1230. Su colega en la emisión es Num(---).

59 Eadem, 135; Monedas Hispánicas, 284.

60 "Tito Livio XLIII, 3 y los nomina de los magistrados monetales de Carteia"..., 89-90.

${ }^{61}$ Véase AbasCAL, 84, y LöRINCZ y Redö, OPEL I, 167. 
lus, Argamonica, Arganta, Arganto, Argantonus, Argea o Argilicus, que se vinculan a la base demográfica autóctona ${ }^{62}$, aunque ninguno de ellos se documenta como nomen.

A partir de la lectura alternativa $\operatorname{Arc}(---)^{63}$, puede pensarse en Arcius. W. Schulze ${ }^{64}$ y H. Solin y O. Salomies ${ }^{65}$ consideran Arcius un nomen plenamente latino. Desde esta óptica, puede defenderse que los $\operatorname{Arc}(i i)$ pudieron ser descendientes de uno de los medio romanos asentados en la colonia o inmigrantes o descendientes de inmigrante.

Por otra parte, $\sqrt{ } *$ arc- es un radical también autóctono, cuyas realizaciones, entre ellas, Arcius, se distribuyen por una amplia área lusitana, galaica y norceltibérica ${ }^{66}$. En opinión de M. L. Albertos ${ }^{67}$, Arcius es una variante meridional de Arquius, nombre bien documentado entre astures y galaicos bracarenses. Pero, en opinión de J. M. Vallejo $^{68}$, no parece verosímil que Arquius y Arcius sean dos variantes (con y $\sin k^{w}$, respectivamente) de la misma raíz, dado que hay zonas, como la galaica, en donde se solapan los testimonios de ambas formas. Pero, a pesar de estas consideraciones, es difícil que los Arc(ii), visto el origen del poblamiento inicial de Carteia, pertenecieran a la población no fenicia residente en el territorio peninsular.

Por lo que respecta a $M$. Arga(---), no hemos hallado nomen alguno con dicho inicio o que coincida con este grupo de cuatro letras. Por ello es lícito pensar en la posibilidad de que se trate del descendiente de un habitante de la Carteia púnica. En este sentido, se documenta el nombre fenicio ' $R Q$, no explicado ${ }^{69}$, que puede desarrollarse 'Arq ('ayin $+r+q$ ), un resultado demasiado cercano a las leyendas monetales $A R G$ / ARC y $A R G A$ como para ignorarlo, pues podría estar documentando que estos Arg/a(---) pudieron ser descendientes de uno de los habitantes púnicos de Carteia integrados en la colonia ${ }^{70}$.

62 Véase J. Untermann, Elementos de un atlas antroponímico de la Hispania Antigua, Madrid, 1965, 193, y M. L. Albertos, La onomástica personal primitiva de Hispania: Tarraconense y Bética, Salamanca, 1966, 33-34; "Correcciones a los trabajos sobre onomástica personal indígena de M. Palomar Lapesa y M ${ }^{a}$ Lourdes Albertos Firmat", Emerita 45, 1977, 40, y "La onomástica de la Celtiberia", en Actas del II Coloquio sobre Lenguas y Culturas Prerromanas de la Península Ibérica, Salamanca, 1979, 138.

63 A. Beltrán, Curso de Numismática, Cartagena, 1950, 445.

${ }^{64}$ Zur Geschichte lateinischer Eigennamen, Berlin, 1933, 126 y 403.

${ }^{65}$ Repertorium nominum..., 21-22.

${ }^{66}$ J. M. VAllejo, Antroponimia indígena ..., 183. En el territorio latino de la Europa romana, LörInCZ y REDö, OPEL I, 165, documentan Arcius, únicamente como cognomen y solo en Hispania.

${ }^{67}$ La onomástica personal primitiva..., 31-32 y 35.

${ }^{68}$ Antroponimia indigena..., 185.

${ }^{69}$ F. L. Benz, Personal names in the Phoenician and Punic inscriptions, Roma, 1972, 174 y 384.

${ }^{70}$ Como defiende J. S. Hernández, "Tito Livio XLIII, 3 y los nomina de los magistrados monetales de Carteia"..., 107. 
L. Atini(us), IIIIvir ${ }^{71}$ de 30 a.C. ${ }^{72}-$ Los pocos Atinii de la Bética ${ }^{73}$ portadores de este nomen de origen etrusco ${ }^{74}$ cuentan con el antecedente nominal de C. Atinius, pretor en $\mathrm{HU}$ en 188 a.C. y propretor en la misma provincia en 187 a.C. ${ }^{75}$. A tenor de los datos, la presencia de C. Atinius tuvo muy poca repercusión en la difusión de su nomen $^{76}$.

En resumen, L. Atini(us) probablemente era descendiente de uno de los medio romanos asentados en la colonia ${ }^{77}$ o quizá inmigrante o descendiente de inmigrante. En cualquier caso, el origen de la familia de este individuo no sería exactamente Etruria, sino Campania, en donde se documentan numerosos Atinii, territorio al que habrían emigrado, entre otros lugares de Italia, miembros de esta gens etrusca desde épocas muy tempranas ${ }^{78}$.

Q. Cornelius [Q.? f.] Gal. Senecio Annianus, inter alia, sacerdos Herculis ${ }^{79}$ y cos. suff. en época de Antonino Pío ${ }^{80} ; \boldsymbol{Q}$. Cornelius Proculus (después L. Stertinius Quintilianus Acilius Strabo Q. Cornelius Rusticus Apronius Senecio Proculus), cos. de $146^{81}$, y sus hijos Q. Cornelius Senecio Proculus, (praetoricius) leg. prov. Asiae ${ }^{82}$, Cornelia Procula y Cornelia Placida ${ }^{83}$.- Los Cornelii de la Bética cuentan con los precedentes nominales de P. Cornelius Scipio (Africanus), magistrado con imperium proconsular en Hispania en 210-206 a.C., L. Cornelius Scipio (Asiaticus), hermano y legado del anterior en 207-206 a.C., L. Cornelius Lentulus, magistrado con imperium proconsular en Hispania en 206-205 a.C. y procónsul en 204-200 a.C., C. Cornelius Cethegus, procónsul en Hispania en 200 a.C., P. Cornelius Scipio (Nasica), pretor en $\mathrm{HU}$ en 194 a.C. y propretor en la misma provincia en 193 a.C., L. Cornelius Dola-

${ }^{71}$ A. Vives, $M H$, CXXVIII, 3-4; O. Gil, $M H E A, \mathrm{n}^{\text {os }} 1815-1816$, y A. Burnett, M. Amandry y P. P. Ripollès, Roman Provincial Coinage, I: From the Death of Caesar to the Death of Vitellius (44 BC-AD 69), London, 1992 (=A. Burnett et al., RPC), $\mathrm{n}^{\text {os }}$ 114-115. L. Atini(us) aparece en compañía de C. Nucia.

${ }_{72}$ F. Chaves, Las monedas hispano-romanas..., 143-144; Monedas Hispánicas, 287.

73 Abascal, 86-87, recoge, incluyendo la variante Atenius, cinco casos, de los cuales cuatro corresponden a la Bética. A estos hay que sumar los dos nuevos Atinii documentados en Corduba (CIL $\left.\mathrm{II}^{2} / 7,417\right)$.

${ }^{74}$ W. Schulze, Zur Geschichte lateinischer Eigennamen..., 68-69, lo estudia en relación con el nomen etrusco Adenna y sus variantes.

75 T. R. S. Broughton, The Magistrates of the Roman Republic, I, Cleveland-Ohio, 1968, 365 y 369.

76 A pesar de ello, Hispania ocupa el primer lugar, con el 35,7\% de los pocos testimonios epigráficos correspondientes al territorio latino de la Europa romana, por delante de la misma Galia Cisalpina; véase LÖRINCZ y REDÖ, OPEL I, 202.

77 J. S. HeRnÁndez, "Tito Livio XLIII, 3 y los nomina de los magistrados monetales de Carteia"..., 93-95.

78 Idem, 94-95.

79 CIL II, 1929.

${ }^{80}$ Véase A. CABallos, Los senadores hispanorromanos y la romanización de Hispania (s. I-III). I: Prosopografía, Écija, 1990, 112-113, y Fr. DEs Boscs-Plateaux, Un partie hispanique à Rome?..., 636637, para las fuentes y demás datos.

81 Véase A. CABallos, Los senadores hispanorromanos..., 106-108, y Fr. DEs Boscs-Plateaux, Un partie hispanique à Rome?..., 590-592, para fuentes y demás datos.

82 Véase A. CABALlos, Los senadores hispanorromanos..., 113-114, para las fuentes y otros aspectos.

${ }^{83}$ CIL VI, 1388; ILS 1090. 
bella, pretor en HU en 100 a.C. y procónsul en la misma provincia en 99-98 a.C., $P$. Cornelius Scipio Nasica, pretor en HU en 93 a.C., y Cornelius Aquinus, legatus de Q. Caecilius Metellus Pius, procónsul en HU en 79-71 a.C. ${ }^{84}$

La repetida presencia en Hispania de miembros de la oligarquía romana con este nomen parece tener un buen reflejo en el hecho de que Cornelius sea el tercer nomen más frecuente en la península Ibérica ${ }^{85}$, que, además, ocupa el primer lugar dentro del territorio latino de la Europa romana por los Cornelii en él documentados epigráficamente $^{86}$.

No se excluye la posibilidad de que llegaran a la península Cornelii vinculados a los negocios, pues se documentan Cornelii en Delos ${ }^{87}$, pero, dada la repetida presencia de Cornelii como magistrados y promagistrados en las tierras hispanas, parece pertinente vincular a los Cornelii en ellas documentados preferentemente con hispani antes que con hispanienses.

Los cognomina que portan estos Cornelii no contradicen esta apreciación. Sobre Senecio ya hemos tratado. Por lo que respecta a Proculus, este cognomen ocupa en Hispania $^{88}$ el puesto séptimo, aunque porcentualmente la difusión en el conjunto del Imperio es algo superior ${ }^{89}$. De todas formas, la alta difusión alcanzada en Hispania por este cognomen se confirma por el primer puesto que ocupa este territorio dentro de la zona latina de la Europa romana ${ }^{90}$.

Por último, Placidus es un cognomen que parece presentar una especial vinculación con Hispania, pues este territorio concentra el porcentaje más elevado de testimonios epigráficos dentro de la zona latina de la Europa romana ${ }^{91}$.

Se ha defendido un origen carteyense para Q. Cornelius [Q.? f.] Gal. Senecio Annianus, sobre el que hemos tratado más arriba, y, por extensión, para $Q$. Cornelius Proculus y sus hijos $Q$. Cornelius Senecio Proculus, Cornelia Procula y Cornelia

${ }^{84}$ T. R. S. Broughton, The Magistrates of the Roman Republic, I..., 280, 287, 291, 296-297, 299300, 302, 307, 312, 317, 320, 324, 343, 348 y 574; The Magistrates of the Roman Republic, II..., 3, 5 y 14 .

85 Véase ABASCAL, 9.

${ }^{86}$ Hispania, con el 34,6 \%, Galia Cisalpina, con el 24,7 \%, y la Narbonense, con el 21,1 \%, ocupan destacadamente los tres primeros lugares; véase LÖRINCZ, OPEL II, 76-78.

87 J.-L. Ferrary, Cl. Hasenohr \& M.-Th. Le Dinahet, “Liste des italiens de Délos” y en Ch. Müller \& Cl. Cl. Hasenohr (eds.), Les italiens dans le monde grec, BCH Suppl. 41, 2002, 193.

${ }_{8}$ En Lusitania, Proculus alcanza parecida difusión como nombre único que como cognomen; véase M. Navarro Caballero, M. Oria Segura \& J. L. Ramírez Sádaba, "La onomástica greco-latina", en M. Navarro Caballero \& J. L. Ramírez Sádaba (coords.), Atlas antroponímico de la Lusitania Romana, Mérida-Bordeaux, 2003, 410.

89 En Hispania, los 148 testimonios epigráficos documentados por ABASCAL, 470-472, representan el 8,02 \%o de todos los recogidos por dicho autor (18.444); en el conjunto del Imperio, en donde ocupa el lugar duodécimo, los 1279 testimonios epigráficos reunidos por I. KaJAnTo, The Latin Cognomina, Helsinki, 1965 (desde ahora Kajanto), 176, representan el 9,61 \%o de todos los reunidos por este autor (133.059). En adelante, los tantos por mil ofrecidos serán siempre en relación a ambas cifras totales.

90 Hispania concentra el 25,5 \%, mientras Galia Cisalpina y Dalmacia alcanzan el 22,8 \% cada una; véase LÖRINCZ, OPEL III, 166.

91 Hispania reúne el 43,2 \% del total de testimonios epigráficos, seguida por Galia Cisalpina, con el 16,2 \%; véase LörINCZ, OPEL III, 144. 
Placida. Pero, aunque ningún dato directo demuestra positivamente que estos $Q Q$. Cornelii fueran carteyenses, los indirectos se inclinan por esta posibilidad.

A. T. Fear ${ }^{92}$ destaca, en primer lugar, que estos $Q Q$. Cornelii pertenecían a la tribu Galeria, cuando la tribu que positivamente se documenta para Carteia es la Sergia ${ }^{93}$ y, en segundo lugar, que la inscripción por la que conocemos a $Q$. Cornelius Senecio Annianus no fue hallada en Carteia, sino en (el desierto de) la antigua casa convento de La Almoraima, aguas arriba del río Guadarranque, al Norte de Carteia, muy cerca de Castellar de la Frontera (Cádiz), a cuyo término municipal pertenece. Ninguno de estos dos argumentos son determinantes. Especialmente el segundo no tiene en cuenta la posibilidad de que los $Q Q$. Cornelii, llegados desde otra población hispana, incluso bética, se asentaran en Carteia ya como ciudadanos romanos.

Por otra parte, ciertamente la inscripción de Q. Cornelius Senecio Annianus nada dice acerca de que fuera sacerdos Herculis concretamente en Carteia. Pero esta posibilidad no debe excluirse, pues la vinculación de Carteia con Herakles-Hércules es un hecho probado ${ }^{94}$, como algunas fuentes literarias antiguas documentan ${ }^{95} \mathrm{y}$ corroboran los datos numismáticos ${ }^{96}$. En concreto, $\mathrm{Cl}$. H. Moore ${ }^{97}$ defiende que su cargo como sacerdos Herculis probablemente le fue conferido por los habitantes de Carteia mientras Q. Cornelius Senecio Annianus servía como legatus legionis VII, aunque la fecha exacta del servicio no puede ser determinada.

Se ha propuesto que $Q$. Cornelius Senecio Annianus actuaba como fenerator ${ }^{98}$, gran prestamista que multiplicaba su dinero por medio del préstamo, el único comer-

92 "Carteia, from colonia latina to municipium C.R.”, en Actas del II Congreso de Historia de Andalucía, Sevilla, 1994, 299.

${ }_{93}$ C(aio) Curvio C(ai) f(ilio) / Ser(gia) Rustico / IIIIvir(o) iterum / Tertius l(ibertus) (IRPCádiz 92).

${ }^{94}$ La estampilla Hercules (CIL II, 1927= CIL II, 6252f) hallada en ladrillos producidos en Carteia hace referencia al nombre del productor, en este caso, un nombre, como indica CH. Rico, "Éléments pour une approche socio-économique de la production de matériaux de construction en terre cuite dans les provinces hispaniques", en M. Bendala, Ch. Rico \& L. Roldán (eds.), El ladrillo y sus derivados en la época romana, Madrid, 1999, 34, reducido a un cognomen que podría reflejar un estatuto de liberto.

95 Estrabón (3.1.7) nos transmite la creencia recogida por Timóstenes de Rodas en Sobre los puertos de que Karteia había sido fundada por Herakles y había tenido antiguamente el nombre de 'Herákleia. Esta mención de Estrabón y la existencia de una figurilla de bronce, en opinión de M. ORIa SEgura, "El Hércules de Carteia en época imperial", Almoraima. Revista de Estudios Campogibraltareños 9, 1993 , 163-174; "Los templos de Hércules en la Hispania romana", AAC 4, 1993, 224-225, son indicios de la existencia de un santuario en principio consagrado a Melqart y después a Hércules.

96 Aunque predomina la cabeza de Júpiter-Saturno y una femenina que, según F. Beltrán Lloris, "Identidad cívica y adhesión al príncipe en las monedas municipales hispanas", en F. Marco, F. Pina \& J. Remesal (eds.), Religión y propaganda política en el mundo Romano (Col. Instrumenta 12), Barcelona, 2002, 168, quizá corresponda a Fortuna, en alguna que otra emisión aparece la de Hércules; véase A. Vives, MH, CXXIX, 6 y 13; L. Villaronga, Corpus nummum Hispaniae ante Augusti aetatem, Madrid, 1994, 413, nº 6, y 417, nº 44; F. Chaves, Las monedas hispano-romanas..., lám. I, a.C. lám. II, 15.C; P. P. Ripollès, Monedas hispánicas..., 222, nos 1377 y 1403.

97 "Oriental Cults in Spain", en D. G. Lyon \& G. F. Moore, Studies in the History of Religions, New York, 1912, 322.

98 J. Andreau, Banque et affaires dans le monde romain (IVé siècle av. J.-C. - III siècle ap. J.-C.), Paris, 2001, 40. 
cio que no fue desdeñado por los romanos ${ }^{99}$, siguiendo un comportamiento propio de las aristocracias terratenientes de sociedades eminentemente agrarias.

Asimismo, conocemos un productor de aceite de nombre Cornelius Proclus ${ }^{100}$, al que tal vez también correspondan los rótulos cursivos Proclus ${ }^{101}$ y Proculus ${ }^{102}$, que quizá pueda identificarse con $Q$. Cornelius Senecio Proculus o con su padre, $Q$. Cornelius Proculus ${ }^{103}$, poseedores, entre otros, de un (fundus) Sul(---) adscrito al control de Astigi, que coincidía, en líneas generales, con la zona del río Genil ${ }^{104}$.

C. Curman(us) / C. Curm(a)n(us), q(uaestor) ${ }^{105}$ de 105 a.C. ${ }^{106}$, y $\boldsymbol{M}$. Cur(manus), magistrado ${ }^{107}$ de 80 a.C. ${ }^{108}$ - Curmanus es un nomen no documentado en otro lugar. Quizá estos Curmani fueron, como defiende J. S. Hernández ${ }^{109}$, descendientes de uno de los habitantes púnicos de la Carteia prerromana que se acogieron a la posibilidad de integrarse en la colonia latina. El único argumento que hemos hallado para verificar esta hipótesis es el nombre púnico $Q R B N$, probablemente relacionado con el nombre hebreo qorbān ('regalo, don') ${ }^{110}$, en el que habría que admitir el fenómeno $/ \mathrm{b} />/ \mathrm{m} /$ medial para que resultase algo cercano a Curmanus.

Q. Curvi(us), q(uaestor) $)^{111}$ de 120 a.C. ${ }^{112}$, y C. Curvius $\boldsymbol{C}$. $\boldsymbol{f}$. Ser. Rusticus, IIIIvir iterum $^{113}$ a finales del siglo I a.C. o inicios del siguiente.- Los Curvii de la Bética, en donde solo se documenta epigráficamente un par de individuos ${ }^{114}$ con este nomen latino ${ }^{115}$, carecen de antecedente nominal entre los magistrados pre-imperiales con man-

99 L. Juglar, Du role des esclaves et des affranchis dans le commerce, Roma, 1972 ${ }^{\mathrm{r}}$ (Paris, 1894¹), xvi-xviii.

100 CIL X, 4274, de 153.

101 CIL X, 4208-4209, de 149; CIL X, 4284, de 153, y CIL X, 4322, de 154.

102 CIL X, 4447, de 140 a 145, y CIL X, 3865, de 149. Véase G. CHIC, Epigrafía anfórica de la Bética. II. Los rótulos pintados sobre ánforas olearias. Consideraciones sobre la Annona, Sevilla, 1988, 96, 107 y 167.

103 A. Caballos, Los senadores hispanorromanos..., 114.

104 G. Chic, Datos para un estudio socioeconómico de la Bética. Marcas de alfar sobre ánforas olearias, Écija, 2001, 10.

105 A. VIVEs, MH, CXXVI, 11-12; O. GIL, MHEA, nos 1222-1223; Monedas Hispánicas, 279.

106 F. Chaves, Las monedas hispano-romanas..., 120.

107 A. Vives, $M H$, CXXIX, 9-10, y O. GIL, MHEA, n ${ }^{\text {os }} 1225-1226$. Su colega en la emisión es $L$. $\operatorname{Ar}(---)$.

108 F. Chaves, Las monedas hispano-romanas..., 133-134; Monedas Hispánicas, 283.

109 "Tito Livio XLIII, 3 y los nomina de los magistrados monetales de Carteia"..., 107.

110 F. L. Benz, Personal names in the Phoenician and Punic inscriptions..., 179 y 406.

111 A. Vives, $M H$, CXXVI, 7, y O. GiL, MHEA, n ${ }^{\circ} 1232$.

112 F. Chaves, Las monedas hispano-romanas..., 118.

113 IRPCádiz 92.

114 Estos dos son igualmente los únicos documentados epigráficamente en toda Hispania; véase Abascal, 126; y en todas las provincias latinas de la Europa romana; véase B. LöRINCz, Onomasticon provinciarum Europae latinarum. Vol. II: Cabalicius-Ixus, Wien 1999 (desde ahora, LöRINCZ, OPEL II), 89.

115 H. Solin y O. Salomies, Repertorium nominum..., 65. 
do en HU. Además, no se atestigua ningún Curvius entre los magistrados del Estado romano de los siglos II-I a.C., indicio de la nula importancia alcanzada por esta gens.

Por su parte, Rusticus ocupa el puesto decimosexto de los cognomina más frecuentes en Hispania ${ }^{116}$, circunstancia que parece concederle la categoría de exitoso entre los indígenas. Y, aunque la frecuencia alcanzada en Hispania casi duplica la del conjunto del Imperio ${ }^{117}$, tampoco es tan infrecuente en este último como para considerarlo un cognomen poco habitual, cuando, por el contrario, sí lo es.

Probablemente, $Q$. Curvi(us) fue descendiente de primera generación de los colonos libertini o inmigrante italiano tempranamente asentado en Carteia. Por su parte, C. Curvius Rusticus no sería sino descendiente del anterior ${ }^{118}$.

P. Falcidius, IIIIvir ${ }^{119}$ de 40 a.C. ${ }^{120}$ - El nomen Falcidius no cuenta con antecedente nominal entre los magistrados pre-imperiales con mando en HU. Además, solo se atestiguan muy pocos Falcidii entre los magistrados del Estado romano de los siglos II-I a.C. ${ }^{121}$ y no parece que ninguno de ellos llegara a gobernar HU en alguno de los años de los que desconocemos la identidad del correspondiente gobernador provincial. Este individuo quizá sea el único Falcidius atestiguado en Hispania, en donde no se documenta epigráficamente ninguno. En la zona latina de la Europa romana, la epigrafía solo testimonia un individuo con este nomen, por cierto, expresado en griego $^{122}$.

Probablemente, P. Falcidius era descendiente de los hijos de romanos e hispanas asentados en la colonia latina, pero no cabe duda de que presenta similares probabilidades de ser inmigrante. En este sentido, J. S. Hernández ${ }^{123}$ defiende que miembros de la gens Falcidia que tuvieron cierta relevancia en el siglo I a.C. podrían haber fijado sus intereses en Hispania, como permite pensar la coincidencia cronológica entre la emisión de P. Falcidius y la época en que esta gens desarrolló sus actividades.

P. Iuli(us), q(uaestor) ${ }^{124}$ de 115 a.C. ${ }^{125}$ - Iulius, aunque no presenta una especial vinculación con Hispania, pues alcanza una gran difusión en todo el Imperio ${ }^{126}$, es el

116 Abascal, 490.

117 En Hispania, los 89 testimonios recogidos por ABASCAL, 490, representan el 4,82 \%o del total. En el conjunto del Imperio, los 344 casos catalogados por KaJANTO, 310, de los cuales, casi el $40 \%$ documentado en África, representan el 2,58 \%o de total.

118 Véase J. S. Hernández, "Tito Livio XLIII, 3 y los nomina de los magistrados monetales de Carteia"..., 90.

119 A. Vives, MH, CXXVIII, 1, y CXXIX, 1; O. Gil, MHEA, nos 1812 y 1814 y A. Burnett et al., $R P C, \mathrm{n}^{\text {os }} 111-112$.

120 F. Chaves, Las monedas hispano-romanas..., 142.

121 C. Falcidius, tribuno de la plebe y legado antes de 66 a.C., y C. (o P.) Falcidius, tribuno de la plebe en 41 a.C.; véase T. R. S. Broughton, The Magistrates of the Roman Republic, II..., 372,469 y 483 .

122 Phalkidios, documentado en Dalmacia (CIL III, 12708); véase LöRINCZ, OPEL II, 134.

123 "Tito Livio XLIII, 3 y los nomina de los magistrados monetales de Carteia"..., 90.

124 A. VIVES, MH, CXXVI, 9-10, y O. GIL, MHEA, $\mathrm{n}^{\text {os }} 1242-1243$.

125 F. Chaves, Las monedas hispano-romanas..., 118-119; Monedas hispánicas, 279.

${ }^{126}$ En la parte latina de la Europa romana, los Iulii alcanzan los mayores porcentajes en la Narbonense $(17,14 \%)$, Hispania (14 \%), Dalmacia (11,4\%), Bélgica-Germania (9,94 \%), Panonia $(9,53 \%)$ e Galia 
nomen más frecuente en la península Ibérica ${ }^{127}$ y tiene como precedentes nominales a C. Iulius Caesar, cuestor en 69 a.C. de C. Antistius Vetus ${ }^{128}$, propretor en HU, y a C. Iulius Caesar Octavianus. Por razones cronológicas obvias, este Iulius no es vinculable con ninguno de los anteriores personajes. Bien al contrario, era descendiente de los hijos de soldados romanos e hispanas asentados en Carteij $^{129}$, si es que no se trataba de un inmigrante o descendiente de inmigrante.

C. Maius C. f. Pollio, IIIIvir ${ }^{130}$ tal vez en 35 a.C. ${ }^{131}$ - Los pocos Maii de la Bética no cuentan con antecedente nominal entre los magistrados pre-imperiales con mando en HU. Además, no se atestigua ningún Maius entre los magistrados del Estado romano de los siglos II-I a.C., de manera que difícilmente algún Maius pudo estar al frente de HU.

En opinión de J. S. Hernández ${ }^{132}$, Maius, que conoce la forma Magius como otra realización del mismo gentilicio, es un nomen de origen osco $^{133}$. En concreto, J. S. Hernández $z^{134}$ defiende que los Maii / Magii eran oriundos de Campania, concretamente de la ciudad de Capua, como se confirma por la presencia de Maii y Magii en las inscripciones de los magistri campani de dicha población, situables entre 112 y 71 a.C. Por lo que respecta a Hispania, el nomen Maius solo se documenta, en la forma femenina, en Olisipo $^{135}$ y $\operatorname{Corduba}^{136}$ y, en la masculina, en este personaje carteyense, que, según J. S. Hernández ${ }^{137}$, pudo ser descendiente de la familia osca que quizá se estableció en la península Ibérica como consecuencia de sus actividades militares o bien por fines comerciales. En este sentido, Maius es considerado un "fósil onomástico" de la emigración itálica ${ }^{138}$.

Pollio fue un cognomen de especial difusión en la costa mediterránea y en la Bética ${ }^{139}$. Se documenta en individuos tanto presumiblemente hispanienses como en personajes probablemente hispanos, por lo que no parece un dato decisorio, aunque el porcentaje alcanzado en el conjunto del Imperio es manifiestamente inferior al alcan-

Cisalpina $(8,77 \%)$, pero se documentan también ampliamente por Aquitania, Nórico, Mesia Inferior, Dacia, Lugdunense, Mesia Superior, Britannia y Retia; véase LöRINCZ, OPEL II, 201-207.

127 Véase ABASCAL, 151.

128 T. R. S. Broughton, The Magistrates of the Roman Republic, II..., 132.

129 J. S. Hernández, "Tito Livio XLIII, 3 y los nomina de los magistrados monetales de Carteia"..., 90-91.

130 A. Vives, $M H$, CXXVIII, 2; O. Gil, MHEA, nº 1810, y A. Burnett et al., RPC, $\mathrm{n}^{\circ} 113$.

131 F. Chaves, Las monedas hispano-romanas..., 142-143; Monedas Hispánicas, 286.

132 "Tito Livio XLIII, 3 y los nomina de los magistrados monetales de Carteia"..., 95.

133 H. Solin y O. Salomies, Repertorium nominum..., 111, lo consideran latino.

134 “Tito Livio XLIII, 3 y los nomina de los magistrados monetales de Carteia"..., 96.

135 CIL II, 235.

136 AE 1985, 419.

137 "Tito Livio XLIII, 3 y los nomina de los magistrados monetales de Carteia"..., 96.

138 M. Navarro Caballero, "Notas sobre algunos gentilicios romanos de Lusitania: una propuesta metodológica acerca de la emigración itálica", en J.-G. Gorges \& T. Nogales (eds.), Sociedad y cultura en la Lusitania romana. IV Mesa Redonda Internacional, Mérida, 2000, 284.

139 J. UnTERMAnN, Elementos de un atlas antroponímico..., 149. 
zado en Hispania ${ }^{140}$, que además ocupa el primer puesto dentro de los territorios latinos de la Europa romana ${ }^{141}$ por el número de testimonios epigráficos documentados.

En resumen, C. Maius Pollio, probablemente era descendiente de los medio romanos asentados en Carteia, aunque pudo ser perfectamente emigrante o descendiente de emigrante.

L. $\underline{\text { Marci(us) / L. Marci(us), magistrado }}{ }^{142}$ de 104 a.C. ${ }^{143}$ - Los Marcii de la Bética tienen unos precedentes nominales muy dispares. Por un lado, el segundón y excesivamente tempranero L. Marcius Septimius, legado de P. Cornelius Scipio (Africanus) en 206 a.C. ${ }^{144}$, y el excesivamente tardío L. Marcius Philippus, gobernador de HU, muy probablemente como procónsul, en 34 a.C. ${ }^{145}$ Entre ambas fechas se sitúa la emisión monetal por la que conocemos a L. Marci(us). De todas formas, no puede negarse definitivamente la posibilidad de que algún Marcius se hallara al frente de HU en 170,165-156, 148, 130, 122-115 ó 104-103, años de los que desconocemos los gobernadores de dicha provincia y durante los cuales los Marcii alcanzaron alguna importancia dentro de la oligarquía romana. En este sentido, cabe destacar que Hispania, con poco más del treinta por ciento del total, se sitúa al frente de los territorios latinos de la Europa romana por el número de Marcii documentados epigráficamente, por delante de Panonia y de la misma Galia Cisalpina ${ }^{146}$.

L. Marci(us) probablemente pertenecía al grupo de los descendientes de hijos de soldados romanos y nativas asentados en Carteia, aunque obviamente pudo ser inmigrante o descendiente de inmigrante. En este sentido, debe destacarse la presencia de varios Marcii en Delos ${ }^{147}$ que testimonian la emigración de individuos con este nomen. Pero, vista la importancia relativa alcanzada por la difusión del nomen en la península Ibérica, no puede negarse de forma absoluta la posibilidad de que algún Marcius terminara siendo gobernador de $\mathrm{HU}$, con la consiguiente difusión de su nomen entre los indígenas.

140 En Hispania, los 30 casos epigráficos recogidos por ABASCAL, 462, representan el 1,62 \%o del total hispano; en el conjunto del Imperio, los 118 casos catalogados por KAJANTO, 164, representan el $0,88 \%$ del total.

${ }^{141}$ Hispania alcanza el $53 \%$ de los testimonios epigráficos documentados en el territorio latino de la Europa romana, por encima de Galia Cisalpina que sólo alcanza poco más del $26 \%$; véase B. LöRINCZ, Onomasticon provinciarum Europae latinarum. Vol. III: Labareus-Pythea (Wien 2000) (desde ahora, Lörincz, OPEL III), 148.

142 A. Vives, MH, CXXVI, 13-14, y O. Gil, MHEA, ${ }^{\text {os }} 1227-1228$.

143 F. Chaves, Las monedas hispano-romanas..., 120-121; Monedas Hispánicas, 279.

144 T. R. S. Broughton, The Magistrates of the Roman Republic, I..., 300.

145 Idem, 412.

146 Véase LörInCZ, OPEL III, 56.

147 J.-L. Ferrary, Cl. Hasenohr \& M.-Th. Le Dinahet, "Liste des italiens de Délos”..., 202. 
C. Mini(us) Q. f., IVvir ${ }^{148}$ en 55 a.C., IIIIvir II ${ }^{149}$ en 50 a.C. ${ }^{150}$ y IIIIvir ter(tium) $)^{151}$ en 45 a.C. ${ }^{152}$.- Los Minii de la Bética, en el caso de que haya alguno más, carecen de antecedente nominal entre los magistrados pre-imperiales con mando en HU. Además, no se atestigua ningún Minius entre los magistrados del Estado romano de los siglos II-I a.C., de forma que es poco asumible que algún miembro de esta gens se hallara al frente de HU durante los siglos II-I a.C.

Los Minii documentados epigráficamente en Hispania, portadores de un nomen derivado de un praenomen de origen $\operatorname{osco}^{153}$, son muy pocos ${ }^{154}$, pues, al carteyense probablemente solo pueda sumarse otro atestiguado en Tarraco ${ }^{155}$. El tarraconense permite interpretar todos los casos como testimonios de inmigrantes o de descendientes de inmigrante. En este sentido, J. S. Hernández ${ }^{156}$ defiende que C. Minius pudo ser descendiente de emigrantes itálicos. F. Chaves ${ }^{157}$ señala que la llegada de este individuo puede remontarse quizá a la época en la que Pompeyo Magno y sus clientelas itálicas llegaron a la península Ibérica, pero J. S. Hernández ${ }^{158}$ piensa que la llegada de los Minii a Carteia se podría remontar incluso a los primeros contingentes llegados a la península Ibérica a principios del siglo II a.C. Pero, esta circunstancia no excluye la probabilidad de que los Minii de Carteia pertenezcan a la base demográfica medio romana medio indígena a la que venimos refiriéndonos repetidamente.

P. Mion(---), IIIIvir ${ }^{159}$ de 60 a.C. ${ }^{160}$ - Mion(---) es un nomen no documentado en otro lugar, de manera que pudo corresponder a un descendiente de uno de los habitantes púnicos de la Carteia prerromana que eligieron vivir en la colonia latina ${ }^{161}$.

C. Nini(us), $q$ (uaestor) ${ }^{162}$ de 110 a.C. ${ }^{163}$ - Los Ninii de la Bética, si es que hay alguno más, no cuentan con antecedente nominal entre los magistrados pre-imperiales con

\footnotetext{
148 A. Vives, $M H$, CXXVIII, 8. Su colega era C. Vibi(us).

149 A. Vives, MH, CXXVIII, 5-9, y O. GiL, MHEA, n ${ }^{\text {os }}$ 1817-1821. En esta emisión también aparece acompañado de C. Vibi(us).

${ }_{150}$ F. Chaves, Las monedas hispano-romanas..., 137-138; Monedas Hispánicas, 284-285.

151 A. VIVES, MH, CXXVIII, 10, y O. GIL, MHEA, $\mathrm{n}^{\text {os }} 1822$.

152 F. Chaves, Las monedas hispano-romanas..., 139; Monedas Hispánicas, 285.

153 J. S. Hernández, "Tito Livio XLIII, 3 y los nomina de los magistrados monetales de Carteia"..., 97.

${ }^{154}$ A pesar del exiguo número de Minii, los dos casos epigráficos documentados sitúan a Hispania solo por detrás de Galia Cisalpina, en donde solo se testimonian cuatro. De hecho, los casos italianos e hispanos son los únicos documentados en la zona latina de la Europa romana; véase LöRINCZ, OPEL III, 82.

155 CIL II, 4118.

156 "Tito Livio XLIII, 3 y los nomina de los magistrados monetales de Carteia"..., 97.

157 Las monedas hispano-romanas..., 45.

158 "Tito Livio XLIII, 3 y los nomina de los magistrados monetales de Carteia"..., 97.

159 A. Vives, MH, CXXIX, 7, y O. GiL, MHEA, nº 1813.

${ }^{160}$ F. Chaves, Las monedas hispano-romanas..., 137.

161 J. S. HeRnÁndez, "Tito Livio XLIII, 3 y los nomina de los magistrados monetales de Carteia"..., 107.

162 A. Vives, $M H$, CXXVII, 2, y O. Gil, MHEA, n 1231.

163 F. Chaves, Las monedas hispano-romanas..., 119.
} 
mando en HU. Además, no se atestigua ningún Ninius entre los magistrados del Estado romano de los siglos II-I a.C. ${ }^{164}$

Ninius es un nomen no documentado en el resto de Hispania, aunque se testimonia bien en Italia ${ }^{165}$. Por su parte, W. Schulze ${ }^{166}$ recoge la forma Ninnius ${ }^{167}$, que corresponde a un nomen osco ${ }^{168}$, de una gens probablemente originaria de Capua $^{169}$.

C. Nini(us) seguramente pertenecía a la base demográfica medio romana medio indígena o era un inmigrante o descendiente de inmigrante.

C. Nucia, IIIIvir ${ }^{170}$ de 30 a.C. ${ }^{171}$ - Nucia, considerado indígena por M. L. Albertos ${ }^{172}$, es un nomen ${ }^{173}$ que no se documenta en otro lugar ${ }^{174}$. Nucia, como defiende J. S. Hernández ${ }^{175}$, probablemente era descendiente de uno de los carteyenses fenopúnicos.

Num(---), magistrado ${ }^{176}$ de 70 a.C. ${ }^{177}$, probablemente emparentado con otro Num(--) documentado epigráficamente en la misma Carteia $^{178}$.- F. Chaves ${ }^{179}$ propone tres desarrollos para Num(---): Numisius, Numerius y Nummius, tres gentilicios bien documentados en la Bética.

J. S. Hernández ${ }^{180}$ destaca que los Numisii se atestiguan en Carthago Nova en una serie de inscripciones, cuya cronología se extiende desde el siglo I a.C. hasta el II d.C., y que, aunque el nomen no se halla entre los lingotes de plomo y por consiguiente su presencia en esta ciudad no puede relacionarse con certeza con actividades vinculadas con este distrito minero, parece verosímil que los Numisii, especialmente por la cantidad de libertos que documentan, poseyeran importantes intereses económicos en Carthago Nova.

Según J. S. Hernández ${ }^{181}$, Num(---) pudo ser descendiente de un oriundo quizás de Campania, pues este es el territorio en el que se atestigua la mayor parte de los

164 Sí se documenta L. Ninnius Quadratus, tr. pl. en 58 a.C.

165 Véase R. S. Conway, The Italic Dialects..., 155, 188, 198, 242, 251 y 271.

166 Zur Geschichte lateinischer Eigennamen..., 229 y 424.

167 LÖRINCZ, OPEL III, 102, sólo recoge dos testimonios epigráficos, uno en Galia Cisalpina y otro en Aquitania.

168 W. Schulze, Zur Geschichte lateinischer Eigennamen..., 311 у 594. 99.

169 J. S. Hernández, "Tito Livio XLIII, 3 y los nomina de los magistrados monetales de Carteia"...,

${ }^{170}$ A. Vives, $M H$, CXXVIII, 3-4; O. Gil, $M H E A, \mathrm{n}^{\text {os }} 1815-1816$, y A. BurnetT et al., RPC, $\mathrm{n}^{\text {os }} 114-$ 115. C. Nucia aparece acompañado de L. Atini(us).

171 F. Chaves, Las monedas hispano-romanas..., 143-144; Monedas Hispánicas, 287.

172 La onomástica personal primitiva..., 171.

173 ABASCAL, 441, lo desarrolla Nucia(nus?) y lo considera cognomen.

${ }^{174}$ Los más cercano es el o la Nuc(---) documentado/a epigráficamente en Aquitania (véase LöRINCZ, OPEL III, 106).

175 "Tito Livio XLIII, 3 y los nomina de los magistrados monetales de Carteia"..., 107.

176 A. Vives, MH, CXXVII, 10, y O. Gil, MHEA, no 1230. Su colega en la emisión era M. Arga(---).

177 F. Chaves, Las monedas hispano-romanas..., 135.

${ }^{178}$ CIL II, 1933.

179 Las monedas hispano-romanas..., 135.

180 "Tito Livio XLIII, 3 y los nomina de los magistrados monetales de Carteia"..., 101-102.

181 Ibidem. 
Numisii y en donde el nomen tuvo una marcada continuidad ${ }^{182}$. De todas formas, o los Numisii emigraron abundantemente a Hispania o los Numisii hispanos fueron más fecundos que los cisalpinos, pues Hispania supera ampliamente a Galia Cisalpina por el número de Numisii epigráficamente testimoniados, con más del cincuenta y dos por ciento de los casos documentados en la zona latina de la Europa romana ${ }^{183}$.

También destaca J. S. Hernández ${ }^{184}$ que la forma Num(erius) no está excluida, porque esta es evolución de la anterior, tras producirse la rotación de la $s$ intervocálica, que supuso a su vez la apertura de $i$ a $e$ (Numisius $>$ Numesius $>$ Numerius). Como en el caso anterior, los Numerii de Hispania superan ampliamente a los atestiguados epigráficamente en Galia Cisalpina ${ }^{185}$.

Respecto a la posibilidad de que la abreviatura pueda desarrollarse como Nummius, J. S. Hernández ${ }^{186}$ señala que un argumento a favor de este desarrollo puede ser la existencia en Valentia de un magistrado monetal de época pre-imperial de igual nomen. Nummius parece ser también un nombre osco, como permite pensar su pervivencia en zonas de habla osca, especialmente en el Samnium y el territorio de los vestinos y, secundariamente, en territorios volsco y falisco ${ }^{187}$. Por otra parte, una inscripción de Delos documenta la presencia de un liberto de un tal Q. Nummius como magister collegii ${ }^{188}$, dato que testimonia la emigración de individuos con este nomen, libres o libertos. Contrariamente a los dos anteriores desarrollos de Num(---), el nomen Nummius, que está muy poco atestiguado en el territorio latino de la Europa romana, dentro de su exigüidad, es algo más abundante en Galia Cisalpina que en Hispania $^{189}$.

De todas formas, se llamara como se llamara, los datos inducen a pensar que Num(--) era descendiente de un medio romano asentado en Carteia o, como otra posibilidad, inmigrante o descendiente de inmigrante.

Q. Ops(ilius) / Opsil(ius), magistrado ${ }^{190}$ de 103 a.C. ${ }^{191}$ - Los Opsilii de la Bética, en el caso de que haya alguno más que este, no cuentan con antecedente nominal entre los magistrados pre-imperiales con mando en HU, ni se atestigua ningún Opsilius entre los magistrados del Estado romano de los siglos II-I a.C.

Opsilius es un derivado de Opsius, nomen de origen osco documentado en inscripciones procedentes principalmente del Samnium y del Bruttium ${ }^{192}$. No se documenta

\footnotetext{
182 Véase R. S. Conway, The Italic Dialects..., 157.

183 Véase LöRINCZ, OPEL III, 106.

184 "Tito Livio XLIII, 3 y los nomina de los magistrados monetales de Carteia"..., 102.

185 Hispania, con el 42,3 \%, y la Narbonense, con el 30,7 \%, ocupan los dos primeros puestos dentro de los territorios latinos de la Europa romana; véase LöRINCZ, OPEL III, 106.

186 "Tito Livio XLIII, 3 y los nomina de los magistrados monetales de Carteia"..., 103-104.

187 Véase R. S. Conway, The Italic Dialects..., 279 y 386.

188 J.-L. Ferrary, Cl. Hasenohr \& M.-Th. Le Dinahet, "Liste des italiens de Délos”..., 205.

189 Véase LöRINCZ, OPEL III, 107.

190 A. VIVES, MH, CXXVII, 3-4, y O. GiL, MHEA, nos 1233-1234; Q. Ops., en la serie A; Q. Opsil., en la serie B.

191 F. Chaves, Las monedas hispano-romanas..., 122; Monedas Hispánicas, 280.

192 W. Schulze, Zur Geschichte lateinischer Eigennamen..., 335, 454 y 522; J. S. Hernández, "Tito Livio XLIII, 3 y los nomina de los magistrados monetales de Carteia"..., 100.
} 
en el resto de Hispania ${ }^{193}$. J. S. Hernández ${ }^{194}$ piensa que los Opsilii son de origen samnita y que, aunque no se conoce ningún miembro de esta gens que se desplazara a Hispania en época pre-imperial, dado el origen osco del nombre y la antigüedad de la acuñación por la que se conoce al magistrado carteyense, los antepasados de $Q$. Opsi(lius) pudieron llegar a la península Ibérica como consecuencia de la emigración itálica de inicios del siglo II a.C. Una posibilidad que se impone es la de su pertenencia al grupo de la primera generación de descendientes de los medio romanos asentados en la colonia latina. Otra es la de que Opsilio fuera un inmigrante o su descendiente.

Q. Pedec(aius) / Pedecai(us), magistrado ${ }^{195}$ de 102 a.C. ${ }^{196}$, y C. Pe(decaius), magistrado ${ }^{197}$ de 75 a.C. ${ }^{198}$ - En opinión de J. S. Hernández ${ }^{199}$, Pedecaius, por cierto, no documentado epigráficamente en la parte latina de la Europa romana ${ }^{200}$, muy probablemente era una forma arcaica del nomen latino ${ }^{201}$ Peducaeus, realización esta última en la que el diptongo ai ya ha evolucionado a ae. Los Pedecaii probablemente pertenecían a la primera y segunda generación, respectivamente, de descendientes de los medio romanos asentados en Cartei $^{202}$, si no eran inmigrantes o sus descendientes.

L. Rai(us), censor $^{203}$ de 95 a.C. ${ }^{204}$ - Los pocos Raii documentados en la Bética no cuentan con antecedente nominal entre los magistrados pre-imperiales con mando en HU. Además, no se atestigua ningún Raius entre los magistrados del Estado romano de los siglos II-I a.C. El nomen parece tener un origen ${ }^{2} \operatorname{so}^{205}$ y se encuentra ampliamente atestiguado en Italia ${ }^{206}$, especialmente en Campania y el Samnio, aunque epigráficamente, dentro de su escasez, Raius está algo más documentado en Dalmacia que en Galia Cisalpina e Hispania, territorios estos últimos que se presentan equilibrados en este sentido ${ }^{207}$.

193 Dentro de la zona latina de la Europa romana, Opsilius solo se atestigua epigráficamente en Britannia; véase LöRINCZ, OPEL III, 114.

194 "Tito Livio XLIII, 3 y los nomina de los magistrados monetales de Carteia"..., 100-101.

195 A. Vives, $M H$, CXXVII, 7-8, y O. GiL, MHEA, ${ }^{\text {os }} 1235-1236$.

196 F. Chaves, Las monedas hispano-romanas..., 123-124; Monedas Hispánicas, 280.

197 A. VIVES, MH, CXXIX, 8.

198 F. Chaves, Las monedas hispano-romanas..., 134.

199 "Tito Livio XLIII, 3 y los nomina de los magistrados monetales de Carteia"...., 91.

200 Véase LörINCZ, OPEL III.

201 H. Solin y O. SALOMIES, Repertorium nominum..., 140.

202 J. S. Hernández, "Tito Livio XLIII, 3 y los nomina de los magistrados monetales de Carteia"..., 91-92.

203 A. Vives, MH, CXXVII, 1, y O. Gil, MHEA, n 1240; acompañado de L. Agri(us).

204 F. Chaves, Las monedas hispano-romanas..., 129.

205 J. S. Hernández, "Tito Livio XLIII, 3 y los nomina de los magistrados monetales de Carteia"..., 99; etrusco para W. Schulze, Zur Geschichte lateinischer Eigennamen..., 217.

206 Véase R. S. Conway, The Italic Dialects..., 12, 155, 161, 188, 198, 242, 251, 276 y 372.

207 Véase LÖRINCZ, OPEL IV, 22. 
Según J. S. Hernández ${ }^{208}$, parece muy probable que el magistrado de la moneda de Carteia pudiera ser descendiente de los Raii campanos, que emigraron a Hispania. J. S. Hernández ${ }^{209}$ asimismo destaca que, aunque esta gens se documenta escasamente en la península Ibérica, se atestigua principalmente en Carteia, Italica ${ }^{210}$ y Carthago $N o v a^{211}$, tres ciudades de temprana romanización, indicio de la temprana presencia de esta familia en Hispania. La idea de inmigración por intereses económicos, sin que se pueda descartar definitivamente la vinculación de este Raius a los colonos de Carteia, se ve reforzada por la documentación de Raii en Delos $^{212}$.

M. Sep(tumius) / Septu(mius), magistrado ${ }^{213}$ de 101 a.C. ${ }^{214}$ - Los Septumii de la Bética no cuentan con antecedente nominal entre los magistrados pre-imperiales con mando en HU. Además, no se atestigua ningún Sept(i/u)mius entre los magistrados del Estado romano del siglo II a.C., pues los Septimii no comenzaron a tener alguna importancia dentro de la oligarquía romana sino a partir del siglo I a.C.

El nomen Sept(i/u)mius alcanzó una amplia difusión en Italia ${ }^{215}$, mientras que, en Hispania, los casos documentados epigráficamente quizá no superen la veintena. $M$. Septu(mius) probablemente pertenecía a la base demográfica colonial ${ }^{216}$, si es que no era inmigrante italiano o su descendiente.

C. Vibi(us), aid(ilis) $)^{217}$ de 65 a.C. en adelante ${ }^{218}$, IIIIvi(r) ${ }^{219}$ en 55 a.C. y IIIIvir II ${ }^{220}$ en 50 a.C. ${ }^{221}$, y quizá Vib(ius) Pac(c)iaecus, probablemente eques ${ }^{222}$, amigo del silano M. Licinius Crassus y rico propietario ${ }^{223}$, y $\mathbf{L}$. Vib(ius) Pac(c)iaecus, probablemente hijo del anterior, prefecto enviado por César al frente de las tropas para levantar el

\footnotetext{
208 “Tito Livio XLIII, 3 y los nomina de los magistrados monetales de Carteia”..., 100.

${ }^{209}$ Ibidem.

210 CIL II, 1129.; véase más adelante.

211 CIL II, 3499; J. M. Abascal y S. F. Ramallo, La ciudad de Carthago Nova: la documentación epigráfica, Murcia, 1997, nº 94; CIL II, 6247, 3.

212 J.-L. Ferrary, Cl. Hasenohr \& M.-Th. Le Dinahet, “Liste des italiens de Délos”..., 212.

213 A. Vives, $M H$, CXXVI, 8, y O. Gil, MHEA, n 1229.

214 F. Chaves, Las monedas hispano-romanas..., 126; Monedas Hispánicas, 281.

215 Véase R. S. Conway, The Italic Dialects..., 155, 198, 343, 375, etc. Fuera de la península itálica,
} epigráficamente alcanza su mayor difusión en Panonia, con 100 testimonios, Galia Cisalpina, con 49, y Dalmacia, con 23; véase LöRINCZ, OPEL IV, 69.

216 J. S. Hernández, "Tito Livio XLIII, 3 y los nomina de los magistrados monetales de Carteia"..., 92.

217 A. Vives, MH, CXVII, 9, y O. Gil, MHEA, nº 1237.

${ }^{218}$ F. Chaves, Las monedas hispano-romanas..., 135; Monedas Hispánicas, 284.

219 A. Vives, $M H$, CXXVIII, 8. Su colega era C. Mini(us).

220 A. Vives, $M H$, CXXVIII, 5-9, y O. GIL, MHEA, ${ }^{\text {os }} 1817-1821$. Su colega nuevamente era $C$. $\operatorname{Mini}(u s)$.

221 F. Chaves, Las monedas hispano-romanas..., 137-138; Monedas Hispánicas, 285. J. S. Hernández, "Tito Livio XLIII, 3 y los nomina de los magistrados monetales de Carteia"..., 104, cree verosímil que edil y cuatuorvir fueran el mismo personaje.

222 F. J. Navarro, "Vibius", en J. M. Roldán (dir.), Diccionario Akal de la Antigüedad hispana, Madrid, 2006, 971.

${ }^{223}$ Plut., Cras., 4-5; Ser. 9.1-5. 
cerco de Ulia-Montemayor ${ }^{224}$ - Los Vibii de la Bética no cuentan con antecedente nominal entre los magistrados pre-imperiales con mando en HU. Ciertamente, se atestiguan algunos Vibii entre los magistrados del Estado romano de los siglos II-I a.C., pero da la impresión de que esta gens adquirió cierta importancia dentro de la oligarquía romana a finales del siglo II.

El gentilicio Vibius deriva de un antiguo praenomen osco que alcanzó una gran difusión por toda Italia centro-meridional, como demuestra la abundante documentación de este nomen en las lenguas y los dialectos hablados en estas zonas ${ }^{225}$. Se documenta, además, entre los magistri Campani ${ }^{226}$ y en varios individuos de Delos ${ }^{227}$. A pesar de la abundancia de Vibii en Italia, hay que admitir la activa emigración de este grupo familiar, pues también se alcanzan elevadas cotas en la documentación epigráfica de otras regiones latinas de la Europa romana, comenzando por la misma Hispania, que ocupa el segundo lugar ${ }^{228}$.

C. Vibius puede ser considerado sin mayores problemas descendiente de sus homónimos campanos instalados en la colonia latina de Carteia en el momento de su creación o de algún inmigrante llegado con posterioridad ${ }^{229}$.

Por lo que respecta a Vibius Pac(c)iaecus, el cognomen que porta solo se documenta epigráficamente en Corduba (CIL II $2 / 7,372$ y 438), en dos casos que son los únicos testimonios epigráficos recogidos por B. Lörincz ${ }^{230}$ dentro del territorio latino de la Europa romana. Este cognomen, según J. S. Hernández ${ }^{231}$, está formado por el radical antroponímico $\sqrt{ } *$ Pacci- y por -aecus, un sufijo céltico que servía para formar el nombre de un fundo a partir del antropónimo del dueño, con una función similar a la del sufijo latino -anus/- $a$, que permitía igualmente formar el nombre de una finca (fundus *Paccianus) o del cortijo correspondiente (villa*Pacciana), y cuya génesis, a partir obviamente de Paccius, estuvo quizá motivada por la forma común con la que la comunidad nombraba a los propietarios y habitantes de este fundus. Por su parte, E. W. Haley ${ }^{232}$ defiende que los Vib(ii) Pac(c)iaeci, que eran originarios de Campania o quizá del territorio mársico, fueron de los más antiguos pobladores de Carteia.

Como en el caso del primer Vibius, los Vibii Pac(c)iaeci pueden ser considerados descendientes de inmigrantes campanos instalados en la colonia latina de Cartei ${ }^{233}$

${ }_{224}$ Bell. Hisp., 3.4, Cic., Ad Att., 12.12.1., Fam., 6.18.2.

225 J. S. Hernández, "Tito Livio XLIII, 3 y los nomina de los magistrados monetales de Carteia"..., 104.

226 CIL I $\mathrm{I}^{2}$ 685; ILLRP 710 (Vibius), CIL I², 675; ILLRP 709 (Vivius); CIL I $\mathrm{I}^{2}$, 683; ILLRP 720 (Vibbius); CIL I², 674; ILLRP 707 (Vibius).

227 J.-L. Ferrary, Cl. Hasenohr \& M.-Th. Le Dinahet, "Liste des italiens de Délos”..., 220.

${ }_{228}$ Galia Cisalpina, con el 40,22 \% del total, Hispania, con el 20,4 \%, y Dalmacia, con el 11,49 \%, ocupan los tres primeros puestos dentro de los territorios latinos de la Europa romana; véase LöRINCZ, OPEL IV, 165.

229 Véase C. Castillo, "Hispanienses e hispani en la Bética“, en Hiberia-Italia, Italia-Hiberia. Convegno Internazionale de Epigrafia e Storia Antica, Milano, 2006, 90-91.

230 OPEL III, 119.

231 "Los Vibii Pac(c)iaeci de la Bética: una familia de hispanienses mal conocida", Faventia, 20, 2, 1999, 169-174.

232 Baetica felix..., 18.

233 J. S. Hernández, "Tito Livio XLIII, 3 y los nomina de los magistrados monetales de Carteia"..., 174. 
o de los primeros colonos. Sin embargo, no podemos documentar inequívocamente su origo carteyense, que parece una opción con altas probabilidades, pero que encuentra un inconveniente no despreciable en el hecho de que la única documentación epigráfica haya aparecido en Corduba, en donde también se documentan otros Vibii. En opinión de J. S. Hernández ${ }^{234}$, la vinculación de los Vibii Pac(c)iaeci con Corduba debió producirse en época posterior, como consecuencia de la colaboración prestada a César por L. Vibius Pac(c)iaecus en la liberación de Ulia, lo que le pudo valer la obtención de ciertos privilegios en el seno de la colonia, tras la victoria cesariana, aunque cabría esperar el mismo tratamiento también en el seno de Ulia, comunidad protagonista de los acontecimientos.

Los miembros atestiguados de la elite carteyense, salvo $L$. $\operatorname{Arg}(---), L$. $\operatorname{Ar}(---), M$. Arga(---), los dos Curman(i), P. Mion(---), C. Nucia, C. Annius Senecio y los $Q Q$. Cornelii, presentan una onomástica que permite proponer que fueron descendientes de los hijos de soldados romanos y nativas hispanas asentados en la colonia o inmigrantes itálicos llegados posteriormente o sus descendientes. Entre ellos se distinguen individuos de orígenes latinos, como los Curvi(i), P. Falcidius, P. Iuli(us), L. Marci(us), Q. Pedec(aius) y M. Sep(tumius); latinos u oscos, como L. Agri(us) y Cn. Am(m)i(us); oscos, como C. Maius Pollio, C. Mini(us), C. Nini(us), Num(---), Q. Ops(ilius), L. Rai(us) y C.Vibi(us); y etruscos, como L. Atini(us ${ }^{235}$.

Por su parte, los dos Curman(i), P. Mion(---) y C. Nucia probablemente eran descendientes de los habitantes de la Carteia púnica que se integraron en la colonia latina.

Por último, Annius Senecio y los $Q Q$. Cornelii parecen inmigrantes hispanos o descendientes de dichos inmigrantes.

R. C. Knapp ${ }^{236}$ propuso en su momento que la lex Iulia de civitate Latinis et sociis danda, aprobada en 90 a.C., y que permitía acceder a la ciudadanía romana a los latinos que no hubiesen participado en la Guerra Social ${ }^{237}$, probablemente tuvo las mismas consecuencias para Carteia que para cada una de las colonias latinas deducidas en Italia al Sur del Po, es decir, su conversión en municipium civium Romanorum. En opinión de A. T. Fear ${ }^{238}$, la afirmación de A. Gelio de que, por aquel tiempo, refiriéndose a 90 a.C., se concedió la ciudadanía a todo el mundo latino ${ }^{239}$ puede ser una confirmación de que Carteia también la recibió. Según R. C. Knapp ${ }^{240}$, el cambio puede seguirse a través de las acuñaciones monetales, en las que la fórmula $E X$ $S$. $C$, vinculable a la categoría de colonia latina, fue sustituida por la de $E X D$. $D$.,

234 Ibidem.

235 M. J. PenA, “Algunos rasgos dialectales del latín de Hispania”..., 399, destaca que buena parte de los osco-umbros que emigraron a Hispania eran gentes provenientes de las zonas montañas de la península italiana, regiones pobres en donde la vida era muy dura y nos invita a recordar que ya A. Tovar, en su obra Latín de Hispania. Aspectos léxicos de la romanización, publicada en Madrid en 1968, llegó a la conclusión de que lo que permiten atisbar los datos históricos y lingüísticos sobre la colonización romana de la península Ibérica refleja un léxico "de humildes colonos, de gente pobre".

236 Aspects of the Roman experience in Iberia. 206-100 B.C., Valladolid, 1977, 120.

237 App., Bell.Civ., 1.49; Cic., Balb., 8.21; Vell., 2.16 у 20.

238 "Carteia, from colonia latina to municipium C.R."..., 300.

239 Au. Gell., N.A. 4.4.3.

240 Aspects of the Roman experience in Iberia..., n. 54. 
propia ya del estatuto municipal. Sin embargo, este conversión estatutaria no pudo coincidir con la sustitución de una fórmula por otra, pues la acuñación que presenta las leyendas CARTEIA // P. FALCIDIVS IIIIVIR EX S C F C ${ }^{241}$ se sitúa en 40 a.C. ${ }^{242}$, y aquella en la que se lee CARTEIA EX D D I/ C. MAIVS C. F. POLLIO IIIIVIR ${ }^{243}$ se fecha en 35 a.C. ${ }^{244}$

Hasta el año 105 a.C., el magistrado carteyense encargado de la acuñación aparece identificado como $q$ (uaestor) ${ }^{245}$. A partir de dicho año y hasta 101 a.C., solo aparecen los nombres de los magistrados en las monedas, pero no la magistratura concreta que ostentaban como encargados de la emisión ${ }^{246}$. Quizá lo hicieron como quaestores. Hasta el año 95 a.C., los encargados de las acuñaciones fueron los censores ${ }^{247}$. Pero, a partir de 90 a.C. ${ }^{248}$, coincidiendo con la promulgación de la lex Iulia de civitate Latinis et sociis danda, y hasta 61 a.C. ${ }^{249}$, los magistrados encargados de las emisiones monetales, cuando así se indicaba en las monedas, pues no ocurría en todas las emisiones, lo hacían como aed(iles). Es probable que este cambio se deba efectivamente a una de las primeras transformaciones internas, realmente inmediata en este caso, de

${ }^{241}$ A. Vives, $M H$, CXXVIII, 1, y CXXIX, 1; O. Gil, MHEA, nos 1812 y 1814, y A. Burnett et al., $R P C, \mathrm{n}^{\mathrm{os}} 111-112$.

${ }^{242}$ F. Chaves, Las monedas hispano-romanas..., 142.

243 A. Vives, $M H$, CXXVIII, 2; O. Gil, $M H E A, \mathrm{n}^{\circ} 1810$, y A. Burnett et al., RPC, $\mathrm{n}^{\circ} 113$.

${ }^{244}$ F. Chaves, Las monedas hispano-romanas..., 142-143. La fórmula EX D D se mantuvo un tiempo, hasta que, en 25 a.C., fue sustituida por simplemente $D$. D., como en la emisión en la que las leyendas se reducen a CARTEIA / D. D.; véase A. VIVES, MH, CXXVIII, 13; F. Chaves, Las monedas hispanoromanas..., IV, a6.B; A. BuRnetT et al., RPC, $\mathrm{n}^{\circ}$ 118; L. Villaronga, Corpus nummum Hispaniae..., $420, n^{\circ} 67$.

${ }^{245}$ (Quidam), q(uaestor) de 125 a.C. (A. Vives, NH, CXXVI, 6); Q. Curvi(us), q(uaestor) de 120 a.C. (A. VIVES, MH, CXXVI, 7, y O. GIL, MHEA, no 1232); P. Iuli(us), q(uaestor) de 115 a.C. (A. VIVES, MH, CXXVI, 9-10, y O. GIL, MHEA, $\mathrm{n}^{\text {os }}$ 1242-1243); C. Nini(us), q(uaestor) de 110 a.C. (A. VIVEs, MH, CXXVII, 2, y O. GIL, MHEA, n ${ }^{\circ} 1231$ ) y C. Curman (us), q(uaestor) de 105 a.C. (A. VIVEs, MH, CXXVI, 11-12, y O. GIL, MHEA, n ${ }^{\text {os }} 1222-1223$ ).

${ }^{246}$ L. Marci(us), de 104 a.C. (A. VIVes, $M H$, CXXVI, 13-14, y O. Gil, MHEA, $\mathrm{n}^{\text {os }} 1227-1228$ ), $Q$. Opsil(ius), de 103 a.C. (A. Vives, MH, CXXVII, 3-4, y O. GIL, MHEA, nos 1233-1234), Q. Pedecai(us), de 102 a.C. (A. VIVes, MH, CXXVII, 7-8, y O. GIL, MHEA, nos 1235-1236), y M. Septu(mius), de 101 a.C. (A. Vives, $M H$, CXXVI, 8, y O. GiL, MHEA, no 1229).

247 (Quidam), ce(n)s(or) de 100 a.C. (A. VIVES, MH, CXXVI, 4); L. Agri(us) y L. Rai(us), censores de 95 a.C. (A. VIVES, MH, CXXVII, 1, y O. GIL, MHEA, $\mathrm{n}^{\circ}$ 1240). Estos censores, cuyas actuaciones estuvieron separadas por cinco años, el mismo lustro que separaría la actuación sucesiva de los duoviri o de los quattuorviri iure dicundo como quinquennales, a partir del momento en el que la lex Iulia municipalis confiara las labores del censo a los magistrados superiores de los municipios, son herederos de los que el Senado romano, poco después de finalizada la Segunda Guerra Púnica, exigió que fueran instituidos a varias colonias latinas de Italia que se habían sustraído a su obligación del envío de contingentes militares, para que realizaran el censo según el sistema romano y enviaran las listas a los censores romanos (Liv. 29.15 y 37). Estos censores, como los carteyenses demuestran, fueron también instituidos en las provincias. Al igual que la realización del censo acabó en manos de los magistrados superiores, como quinquennnales, también la emisión de monetario, realizada por estos magistrados que actuaban como censores, acabó en manos de los anteriores.

${ }^{248} C n . A m(m) i(u s)$ y $L . A r g(--)$, aed(iles) de 90 a.C. (A. Vives, MH, CXXVII, 5-6, y O. GiL, MHEA, $\left.\mathrm{n}^{\mathrm{os}} 1238-1239\right)$.

${ }^{249}$ C. Vibi(us), aid(ilis) de 65 a 61 a.C. (A. Vives, MH, CXVII, 9, y O. GIL, MHEA, nº 1237). 
la adecuación administrativa al nuevo marco jurídico planteado por la obtención de la ciudadanía romana.

A partir de 60 a.C., el mismo año durante cuyo verano C. Julio César regresó a Roma desde HU, en donde había desarrollado la propretura durante el año anterior, los magistrados encargados de las emisiones de Carteia fueron, en todos los casos, IIIIviri ${ }^{250}$, cambio que podemos pensar fue resultado de la paulatina adecuación a una normativa general sobre administración local que habría ido desarrollándose durante el siglo I a.C. y que progresivamente iría imponiéndose por el territorio del Estado romano. En el caso concreto de Carteia, esta adecuación quizá fue consecuencia inmediata de la gestión de César en $\mathrm{HU}^{251}$. La paulatina adecuación a las exigencias de esta normativa quizá explique el cambio producido en las leyendas monetales carteyenses, en las que ex S(enatus) c(onsulto), fórmula que indicaba el órgano supremo de gobierno local del que emanaba la orden para realizar la acuñación, de la que se encargaban el IIIIvir (aedilis) o los IIIIviri (aediles) correspondientes ${ }^{252}$, fue sustituida por la de ex d(ecreto) d(ecurionum) ${ }^{253}$, que expresaba el mismo hecho, pero adecuándose a una terminología que acabó por imponerse a la hora de referirse a las órdenes dictadas por el órgano supremo de gobierno local, habitualmente llamado ordo decurionum ${ }^{254}$.

${ }^{250}$ P. Mion(---), IIIIvir de 60 a.C. (A. VIVEs, MH, CXXIX, 7, y O. GIL, MHEA, no 1813); C. Vibi(us), IIIIvi(r) en 55 a.C. y C.Mini(us), IVvir en el mismo año (A. VIVEs, NH, CXXVIII, 8); C. Vibi(us), IIIIvir, y C. Mini(us), IIIIvir, ambos II IV(viri), en 50 a.C. (A. VIves, NH, CXXVIII, 6-7); C. Mini(us) Q.f., IIIIvir ter(tium) en 45 a.C. (A. VIVES, MH, CXXVIII, 10, y O. GIL, MHEA, nos 1822).

${ }^{251}$ Sabemos por Cicerón que se rumoreaba que César, en 51 a.C., había invitado a las comunidades de la Transpadana a elegir quattuorviri (Cic. Ad Att. 5.2.3) en lugar de duoviri.

${ }^{252}$ P. Falcidius, IIIIvir de 40 a.C., ex S(enatus) c(onsulto) f(aciendum) c(uravit) (A. Vives, $M H$, CXXVIII, 1, y CXXIX, 1; O. GIL, MHEA, $\mathrm{n}^{\circ \mathrm{s}} 1812$ y 1814 y A. BuRNETT et al., RPC, $\mathrm{n}^{\text {os }} 111-112$ ).

253 C. Maius C. f. Pollio, IIIIvir de quizá 35 a.C., ex d(ecreto) d(ecurionum) (A. Vives, MH, CXXVIII, 2; O. GIL, MHEA, no 1810, y A. BuRNeTt et al., RPC, $\left.\mathrm{n}^{\circ} 113\right)$; L. Atini(us) y C. Nucia, IIIIvir(i) de 30 a.C. (A. VIVEs, MH, CXXVIII, 3-4; O. Gil, MHEA, $\mathrm{n}^{\text {os }} 1815-1816$, y A. BuRNETt et al., RPC, $\mathrm{n}^{\text {os }}$ 114-115), etc.

${ }^{254}$ A lo largo de este proceso, se produjo la atribución de la responsabilidad de la acuñación de moneda a cada vez cargos más elevados, pues esta facultad pasó de los quaestores a los (quatturoviri) aediles y de estos a los quattuoruiri iure dicundo, que se encargaron de la acuñación de moneda generalmente como quinquennales. 